\title{
Near-infrared light-triggered nano-prodrug for cancer gas therapy
}

\author{
Runcong Liu ${ }^{1 \dagger}$, Yongjun Peng ${ }^{1 \dagger}$, Ligong Lu' ${ }^{1}$ Shaojun Peng ${ }^{1 *}$, Tianfeng Chen ${ }^{2 *} \mathbb{B}$ and Meixiao Zhan ${ }^{1 *}$
}

\begin{abstract}
Gas therapy (GT) has attracted increasing attention in recent years as a new cancer treatment method with favorable therapeutic efficacy and reduced side effects. Several gas molecules, such as nitric oxide (NO), carbon monoxide (CO), hydrogen $\left(\mathrm{H}_{2}\right)$, hydrogen sulfide $\left(\mathrm{H}_{2} \mathrm{~S}\right)$ and sulfur dioxide $\left(\mathrm{SO}_{2}\right)$, have been employed to treat cancers by directly killing tumor cells, enhancing drug accumulation in tumors or sensitizing tumor cells to chemotherapy, photodynamic therapy or radiotherapy. Despite the great progress of gas therapy, most gas molecules are prone to nonspecific distribution when administered systemically, resulting in strong toxicity to normal tissues. Therefore, how to deliver and release gas molecules to targeted tissues on demand is the main issue to be considered before clinical applications of gas therapy. As a specific and noninvasive stimulus with deep penetration, near-infrared (NIR) light has been widely used to trigger the cleavage and release of gas from nano-prodrugs via photothermal or photodynamic effects, achieving the on-demand release of gas molecules with high controllability. In this review, we will summarize the recent progress in cancer gas therapy triggered by NIR light. Furthermore, the prospects and challenges in this field are presented, with the hope for ongoing development.
\end{abstract}

\section{Introduction}

Cancer is one of the most serious diseases that threaten human health worldwide [1-5]. At present, cancer treatments mainly include surgery, chemotherapy and radiotherapy, but the clinical benefits are unsatisfactory owing to the heterogeneity and complexity of cancer [6-9]. In recent years, as a new cancer treatment model, gas therapy has played important roles in cancer treatment with high therapeutic efficiency [10-14]. The commonly used therapeutic gas molecules include nitric oxide (NO), carbon monoxide $(\mathrm{CO})$, hydrogen $\left(\mathrm{H}_{2}\right)$, hydrogen sulfide

\footnotetext{
*Correspondence: henry2008_ok@126.com; tchentf@jnu.edu.cn; zhanmeixiao1987@126.com

${ }^{\dagger}$ Runcong Liu and Yongjun Peng contributed equally to this work

1 Zhuhai Precision Medical Center, Guangdong Provincial Key Laboratory of Tumor Interventional Diagnosis and Treatment, Zhuhai Hospital Affiliated With Jinan University (Zhuhai People's Hospital), Jinan University, Zhuhai 519000, Guangdong, P.R. China

${ }^{2}$ College of Chemistry and Materials Science, Guangdong Provincial Key Laboratory of Functional Supramolecular Coordination Materials and Applications, Jinan University, Guangzhou 510632, China
}

$\left(\mathrm{H}_{2} \mathrm{~S}\right)$, and sulfur dioxide $\left(\mathrm{SO}_{2}\right)$ (Scheme 1). The development of the first biomedical gas, NO, led to the Nobel Prize in Physiology and Medicine in 1998 for its significant therapeutic effects on cardiovascular diseases [15]. Subsequently, other therapeutic gas molecules have also been used in biomedical applications, especially cancer treatment. Although gas therapy has made great progress in the treatment of diseases, most therapeutic gases are prone to nonspecific distribution after systemic administration, resulting in strong irritation to the respiratory system and severe side effects on normal tissues $[10,16]$. Furthermore, the off-targeting phenomenon of gas molecules often leads to inferior tumor accumulation and weakens therapeutic efficiency [17]. Therefore, the development of stimulus-responsive gas-releasing nanoplatforms (GRNs) for controlled gas release is the main goal that needs to be achieved before the clinical application of gas therapy $[18,19]$. Stimulus-responsive GRNs could effectively prevent gas from being released prematurely in blood circulation or in normal tissues, preventing possible toxicity and side effects $[20,21]$. Furthermore, original author(s) and the source, provide a link to the Creative Commons licence, and indicate if changes were made. The images or other third party material in this article are included in the article's Creative Commons licence, unless indicated otherwise in a credit line to the material. If material is not included in the article's Creative Commons licence and your intended use is not permitted by statutory regulation or exceeds the permitted use, you will need to obtain permission directly from the copyright holder. To view a copy of this licence, visit http://creativecommons.org/licenses/by/4.0/. The Creative Commons Public Domain Dedication waiver (http://creativeco mmons.org/publicdomain/zero/1.0/) applies to the data made available in this article, unless otherwise stated in a credit line to the data. 


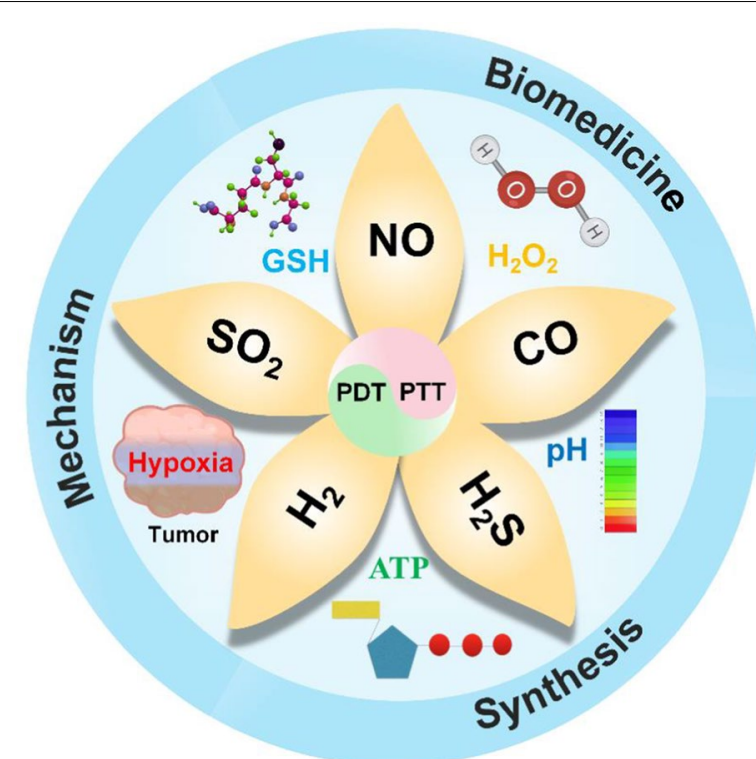

Scheme 1 Schematic illustration of NIR light triggered nano-prodrug for cancer gas therapy

stimulus-responsive GRNs could target tumor tissues and release gas molecules in a controlled manner, significantly enhancing the antitumor effect. There are two main approaches to stimulating the release of gas molecules: (1) endogenous stimuli, such as weak acidity and high $\mathrm{H}_{2} \mathrm{O}_{2}$, glutathione (GSH), ATPase (ATP) and special enzyme levels; and (2) exogenous stimuli, such as light, sound, electricity and magnetism [22-27]. The response to internal stimuli can realize the controlled release of gas without external stimulation, which is simple and convenient without damage to normal tissues [28-31]. In contrast, an external stimulus source has the advantage of easy control of the stimulus source to accurately control the gas release rate, quantity and tissue retention $[22,23,32]$. Among exogenous stimuli, lasers have the advantages of convenience and effectiveness, leading to the wide application of photocontrolled GRNs [33-37]. Compared to ultraviolet or visible light with limited tissue penetration depth, NIR light has higher tissue penetration depth and lower phototoxicity and therefore exhibits broader application prospects in cancer gas treatment [38-40].

NIR can not only trigger the controlled release of gas molecules from GRNs but also achieve phototherapy, including photothermal therapy (PTT) and photodynamic therapy (PDT), for combined antitumor efficacy [41]. PTT uses a photosensitizer to convert absorbed light energy into thermal energy, which produces local high temperatures to destroy tumor cells [42-50]. PTT has the advantages of low invasiveness, deep tissue penetration, high spatiotemporal precision and low cytotoxicity [5157]. Compared to PTT, PDT has a more complex basic mechanism. PDT can induce the apoptosis of cancer cells by stimulating the production of reactive oxygen species (ROS), such as hydroxyl radicals, singlet oxygen and superoxide dismutase, after irradiation with ultraviolet or NIR light [58-63]. ROS can also increase the permeability of the tumor cell membrane and enhance nanoparticle uptake, a phenomenon known as photochemical internalization [64-67]. The precise release of gas molecules from GRNs in diseased tissue is a prerequisite to ensure the effectiveness and biosafety of gas therapy [18, 19]. At present, many kinds of GRNs have been designed to transport gas to tumor tissues, such as poly(D-L-lacticco-glycolic acid) (PLGA), micelles, silica/mesoporous silica, organosilica, $\mathrm{MnO}_{2}$, graphene, $\mathrm{Bi}_{2} \mathrm{Se}_{3}$, upconversion nanoparticles (UCNPs), and $\mathrm{CaCO}_{3}[20]$. In addition, some GRNs can be loaded with antineoplastic drugs that can accumulate in the tumor through the enhanced permeability and retention (EPR) effect or active targeting and regulate relevant proteins to reverse the multidrug resistance (MDR) of tumor cells, thus enhancing the antitumor effects of chemotherapeutic drugs [68-70]. Due to the diversity of therapeutic gases and treatment mechanisms, GRNs could achieve efficient therapeutic effects and reduce side effects at the same time [71, 72]. Table 1 summarizes the applications of various representative NIR-responsive gas prodrugs in tumors in recent years.

In this review, the latest progress in gas prodrugs excited by NIR lasers in tumor therapy is systematically reviewed. First, the reasonable design of multifunctional GRNs is introduced. Second, the advantages of GRNs, including five gas molecules (NO, $\mathrm{CO}, \mathrm{H}_{2}, \mathrm{H}_{2} \mathrm{~S}, \mathrm{SO}_{2}$ ), in tumor therapy under NIR laser irradiation are summarized. Then, combinations of gas therapy with PTT and PDT are introduced, which reveals the synergistic antitumor mechanism of GRNs. Finally, the challenges and possible solutions of gas therapy under NIR laser radiation are discussed.

\section{NIR light-triggered NO prodrug}

$\mathrm{NO}$ was the first gas signaling molecule used and was found to play important roles in a series of physiological processes, such as apoptosis, angiogenesis, and immune response [111-116]. In addition NO can deplete collagen through inducing matrix metalloproteinases (MMP), which has been used for improved nanoparticle penetration in solid tumors $[117,118]$. The physiological function and clinical application of $\mathrm{NO}$ have a longer research history than those of other gas molecules [119]. NO plays a dual role in tumor therapy: it can promote cancer growth at low concentrations $(<1 \mu \mathrm{M})$ but exhibits antitumor effects at high concentrations $(>1 \mu \mathrm{M})$ [120-122]. 
Table 1 Representative NIR-responsive nano-gas prodrugs and their biomedical applications

\begin{tabular}{|c|c|c|c|c|}
\hline Gas & Materials & Tumor cells lines & Therapy & References \\
\hline NO & $\begin{array}{l}\text { RBS-UCNPs } \\
\text { GO-BNN } \\
\text { Me-RBSs } \\
\mathrm{Nb}_{2} \mathrm{C}-\mathrm{MSN} \text { S-SNO } \\
\mathrm{BNN} \mathrm{Bi}_{2} \mathrm{~S}_{3} \\
\mathrm{Fe}_{3} \mathrm{O}_{4} @ P D A @ R u-N O @ F A \\
\text { PTNGs } \\
\text { PNOC-PDA/DOX } \\
\text { DTX@m-PB-NO } \\
\text { SPNsPFTDPP } \\
\text { LysO-Ru-NO@FA@C-TiO } 2 \\
\text { L-Arg@PCn@Mem } \\
\text { DPP-NF } \\
\text { ADAu@CuS YSNPs }\end{array}$ & $\begin{array}{l}\text { Human breast cancer MCF-7/DOXR cells } \\
\text { Human osteosarcoma 143B cells } \\
\text { Human breast cancer 4T1-LUC cells } \\
\text { Mouse breast cancer 4T1 cells } \\
\text { Human liver cancer BEL-7402 cells } \\
\text { Human cervical carcinoma HeLa cells } \\
\text { Human breast cancer MCF-7/ADR cells } \\
\text { Human breast cancer MCF-7/ADR cells } \\
\text { Mouse breast cancer 4T1 cells } \\
\text { Human breast cancer MCF-7 cells } \\
\text { Human breast cancer MCF-7 cells } \\
\text { Mouse breast cancer 4T1 cells } \\
\text { Human cervical cancer HeLa cells } \\
\text { Human breast cancer MCF-7/ADR cells }\end{array}$ & $\begin{array}{l}\text { PTT } \\
\text { PTT } \\
\text { PTT } \\
\text { PTT } \\
\text { PTT } \\
\text { PTT } \\
\text { PTT } \\
\text { PTT } \\
\text { PTT } \\
\text { PTT } \\
\text { PDT } \\
\text { PDT } \\
\text { PDT } \\
\text { PDT }\end{array}$ & $\begin{array}{l}{[73]} \\
{[74]} \\
{[75]} \\
{[76]} \\
{[77]} \\
{[78]} \\
{[79]} \\
{[80]} \\
{[81]} \\
{[82]} \\
{[83]} \\
{[84]} \\
{[85]} \\
{[86]}\end{array}$ \\
\hline $\mathrm{CO}$ & $\begin{array}{l}\text { m-PB-CO } \\
\text { PdNS-CO } \\
\text { POM-anchored HMON } \\
\text { FeCO-DOX@MC } \\
\text { MCM@PEG-CO-DOX } \\
\text { PEG@DW/BC } \\
\text { CORM@G }{ }_{3} \text { DSP-CE } 6 \\
\text { Uio-BDP-MnCO } \\
\text { PB-CO-TPZ } \\
\text { PPPPB-CO-Dox NPs } \\
\text { NCu-FleCP } \\
\text { Fe(CO) } @ \text { @Au }\end{array}$ & $\begin{array}{l}\text { Human cervical cancer HeLa cells } \\
\text { Human lung cancer A549 cells } \\
\text { Human malignant glioma U87MG cells } \\
\text { Mouse breast cancer 4T1 cells } \\
\text { Human colon tumor HCT116 cells } \\
\text { Mouse colorectal cancer CT26 cells } \\
\text { Mouse breast cancer 4T1 cells } \\
\text { Human breast cancer MCF-7 cells } \\
\text { Mouse breast cancer 4T1 cells } \\
\text { Human breast cancer MCF-7/ADR cells } \\
\text { Mouse breast cancer 4T1 cells } \\
\text { Mouse breast cancer 4T1 cells }\end{array}$ & $\begin{array}{l}\text { PTT } \\
\text { PTT } \\
\text { PTT } \\
\text { PTT } \\
\text { PTT } \\
\text { PTT } \\
\text { PTT } \\
\text { PTT } \\
\text { PDT } \\
\text { PDT } \\
\text { PDT } \\
\text { PDT }\end{array}$ & $\begin{array}{l}{[87]} \\
{[88]} \\
{[89]} \\
{[90]} \\
{[91]} \\
{[92]} \\
{[93]} \\
{[94]} \\
{[95]} \\
{[96]} \\
{[97]} \\
{[98]}\end{array}$ \\
\hline $\mathrm{H}_{2} \mathrm{~S}$ & $\begin{array}{l}\text { SP-loaded PEG-UCNPs } \\
\text { rGO-PEI-DTC } \\
\text { AB-DS@BSA-N } \\
\text { ZnS@ZIF-8 }\end{array}$ & $\begin{array}{l}\text { Human breast cancer MCF-7 cells } \\
\text { Human breast cancer MCF-7 cells } \\
\text { Human laryngeal cancer Hep2 cells } \\
\text { Human hepatocellular carcinoma Huh7 cells }\end{array}$ & $\begin{array}{l}\text { PTT } \\
\text { PTT } \\
\text { PTT } \\
\text { PDT }\end{array}$ & $\begin{array}{l}{[99]} \\
{[100]} \\
{[101]} \\
{[102]}\end{array}$ \\
\hline $\mathrm{H}_{2}$ & $\begin{array}{l}\text { PdH-MOF } \\
\text { mPDAB NPs } \\
\text { Z-scheme SnS1.68-WO2.41 } \\
\text { UCCZ NPs }\end{array}$ & $\begin{array}{l}\text { Human cervical cancer HeLa cells } \\
\text { Mouse breast cancer } 4 \mathrm{~T} 1 \text { cells } \\
\text { Mouse breast cancer } 4 \mathrm{~T} 1 \text { cells } \\
\text { Mouse breast cancer } 4 \mathrm{~T} 1 \text { cells }\end{array}$ & $\begin{array}{l}\text { PTT } \\
\text { PTT } \\
\text { PTT } \\
\text { PDT }\end{array}$ & $\begin{array}{l}{[103]} \\
{[104]} \\
{[105]} \\
{[106]}\end{array}$ \\
\hline $\mathrm{SO}_{2}$ & $\begin{array}{l}\text { DNs-Naph-Cbl } \\
\text { RUCSNs-DM } \\
\text { Au-Ag-BTS HTNs } \\
\text { GNRS@PDA-BTS }\end{array}$ & $\begin{array}{l}\text { Human breast cancer MDA-MB-231 cells } \\
\text { Human colon cancer S180 cell } \\
\text { Mouse breast cancer } 4 \mathrm{~T} 1 \text { cells } \\
\text { Human breast cancer MCF-7 cells }\end{array}$ & $\begin{array}{l}\text { PTT } \\
\text { PDT } \\
\text { PDT } \\
\text { PDT }\end{array}$ & $\begin{array}{l}{[107]} \\
{[108]} \\
{[109]} \\
{[110]}\end{array}$ \\
\hline
\end{tabular}

Therefore, tumor growth can be effectively inhibited by raising the concentration of $\mathrm{NO}$ above the basic level in tumor tissues. In addition, NO can enhance the therapeutic effects of chemotherapeutic drugs by overcoming the MDR of cancer cells, and it can improve the efficacy of PDT by reacting with ROS to form highly toxic peroxynitrites [84]. In exogenous stimulation wiht NIR laser irradiation, the position, duration and dose of the light source can be accurately controlled, offering practical application value in biomedical use.

\section{Photothermal therapy-triggered NO prodrug}

Photothermal therapy is the use of NIR light radiation lesions of organic or inorganic nanomaterials to generate local heat in the tumor, stimulating the release of $\mathrm{NO}$ in gas therapy $[123,124]$. At present, various NO prodrugs have been developed, including organic nitrates/nitrites,
metal-NO complexes, nitrosamines, and S-nitrosomercaptan. Moreover, the photothermal conversion and thermosensitive properties give these $\mathrm{NO}$ nanoprodrugs the ability to absorb NIR and convert it into heat, thus promoting the breaking of chemical bonds to release NO [125]. Therefore, various methods to release NO by using the photothermal effect produced by NIR have been developed in recent years. For example, Zhao et al. reported an NIR-triggered NO release platform based on UCNPs and photosensitive ruxin black salts (RBS-UCNPs), which can capture $980 \mathrm{~nm}$ NIR photons and convert them into higher-energy Ultraviolet-visible (UV-vis) photons. In addition, the white upconversion emission causes the maximum spectrum to overlap with the absorption peak of RBS, and then the effective photolysis of NO is induced by the energy transfer (ET) process under irradiation with a $980 \mathrm{~nm}$ laser. This work 
proved that a high concentration of NO produced by high-intensity NIR can directly kill cancer cells, while a low concentration of NO can overcome MDR in chemotherapy by inhibiting the expression of P-glycoprotein (P-gp) on the cancer cell membrane (Fig. 1a) [73]. Although the nanodrugs designed by Zhao et al. have a good NIR response and significant antitumor MDR, they have a low drug loading rate and poor light transmission efficiency (NIR-UV light). High-power NIR laser irradiation is usually required to produce enough $\mathrm{NO}$, which inevitably leads to potential thermal damage. To solve this problem, Chen et al. constructed a novel sandwich nanodrug (GO-BNN6) with NIR light response by $\pi-\pi$ stacking of graphene oxide (GO) nanoparticles with an NO donor (BNN6) that has high drug loading and thermal stability. GO can absorb NIR photons of $808 \mathrm{~nm}$ into active electrons, inducing BNN6 decomposition to release NO, which has significant anticancer effects. Importantly, GO-BNN6 nanopharmaceuticals have repeatable NIR-controlled NO release and high sensitivity to NIR radiation power density, which helps to achieve accurate on-demand release of $\mathrm{NO}$ while reducing the risk of NO poisoning [74].

According to previous studies, the antitumor effect of NO is closely related to its concentration [126]. However, NO molecules have a short half-life under physiological conditions and are easily consumed by free radicals or biological macromolecules [127]. Therefore, it is difficult to achieve effective concentrations of $\mathrm{NO}$ in the tumor area [126, 127]. In another study, Qian et al. developed a fast, simple and efficient coordination precipitation route for insoluble metal ruxin black salts (MeRBs), which have a stable photoresponse, low cytotoxicity and high thermal stability. Under $808 \mathrm{~nm}$ laser stimulation, Me-RBS can absorb light energy and stimulate the release of NO as needed. However, when the NIR light irradiation was stopped, NO release stopped almost completely. This confirms that the release of NO by $\mathrm{Cu}-\mathrm{RBS}$ has high NIR controllability. In addition, in the mouse 4T1-Luc breast cancer model, compared with the blank control group, the NIR irradiation alone group and injection of $\mathrm{Cu}-\mathrm{RBS}$ alone group had no significant inhibitory effect on the growth of primary 4T1-Luc tumors in mice. However, the combined injection of Cu-RBS and NIR light significantly inhibited the growth of primary 4T1-Luc tumors in. Bioluminescence imaging and Masson and H\&E staining analyses of pulmonary metastasis clearly showed proliferative cancer nodules in the three control groups (PBS, NIR, Cu-RBS), but no obvious cancer nodules were seen in the $\mathrm{Cu}$-RBS + NIR group. In brief, $\mathrm{Cu}$ RBS, as a NO donor stimulated by NIR, can effectively inhibit the growth and metastasis of metastatic breast cancer (Fig. 1b) [75]. Recently, Xu et al. proposed their own design of an NO release nanoreactor based on an $\mathrm{Nb}_{2} \mathrm{CMXene}$ nanosheet and a $\mathrm{NO}$ donor (S-nitrosomercaptan, RSNO). Compared to other NO donors, RSNO has the unique advantage of high biocompatibility. Under the irradiation of $1064 \mathrm{~nm}$ laser, MXene can produce heat shock, which triggers the breakage of S-NO bond in RSNO to release NO precisely. This effectively increases the concentration of $\mathrm{NO}$ in the tumor area and further induces apoptosis.In addition, NB2C-MSNS-SNO has excellent PA imaging effect. With the increase of concentration and time, the contrast of PA imaging becomes higher, which can be used as an excellent PA contrast agent.At the same time, the nanomedicine has good biocompatibility and can be quickly eliminated from the body by the kidney, which has great potential for clinical transformation (Fig. 1c) [76].

In addition, Zhao et al. combined bismuth sulfide $\left(\mathrm{Bi}_{2} \mathrm{~S}_{3}\right)$ nanoparticles as carriers with the NO donor bis$\mathrm{N}$-nitroso compound (BNN) to construct efficient NIRtriggered NO-releasing nanocomposites. $\mathrm{Bi}_{2} \mathrm{~S}_{3}$ can be targeted to tumor tissue, converting the light energy of the $1064 \mathrm{~nm}$ laser into thermal energy to trigger BNN decomposition and the release of NO. At the same time, NO can maintain the expression of p62 gene to inhibit protective autophagy, which could enhance the efficacy of PTT by aggravating thermal injury (Fig. 1d) [77]. Among many NO donors, ruthenium nitrite $(\mathrm{Ru}-\mathrm{NO})$ not only has good biocompatibility and low cytotoxicity under physiological conditions but also releases NO controllably under NIR light irradiation [128, 129]. Therefore, Liu et al. covalently linked a Ru-NO donor to the Folic Acid (FA) targeting group on the $\mathrm{Fe}_{3} \mathrm{O}_{4} @ P D A$ magnetic carrier to construct a new multifunctional magnetic nanoplatform that can produce an obvious photothermal effect under $808 \mathrm{~nm}$ laser irradiation, which stimulates the release of NO. Moreover, the nanoplatform can target and be transported to tumor cells under the guidance of a magnetic field and FA targeting groups, which has obvious antitumor effects (Fig. 1e) [78].

The MDR of tumor cells is one of the main obstacles leading to failure of tumor chemotherapy [130]. According to recent studies, overexpression of P-glycoprotein (P-gp) in tumor cells can cause chemotherapeutic drugs (such as doxorubicin and paclitaxel) to be pumped out of the cells [131]. However, NIR stimulation-responsive polymer nanoparticles (such as drug-loaded or drugbound nanoparticles) can overcome MDR by inhibiting the expression of P-gp. Therefore, Yang et al. developed a $\mathrm{Fe}_{3} \mathrm{O}_{4} @$ polydopamine photothermal platform with high drug loading, which was directly triggered by $808 \mathrm{~nm}$ laser irradiation to efficiently release $\mathrm{NO}$ and reduce the expression of the P-gp protein, overcoming the MDR of tumor cells during chemotherapy [79]. At present, several 
a

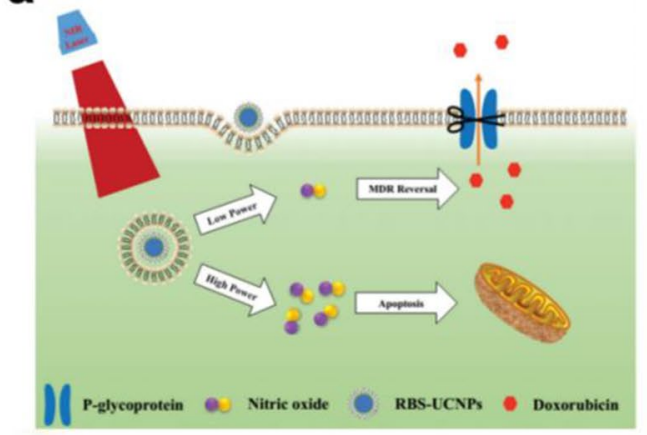

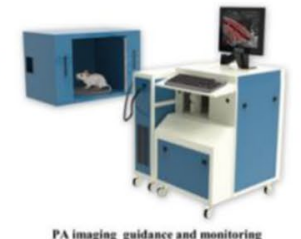

d
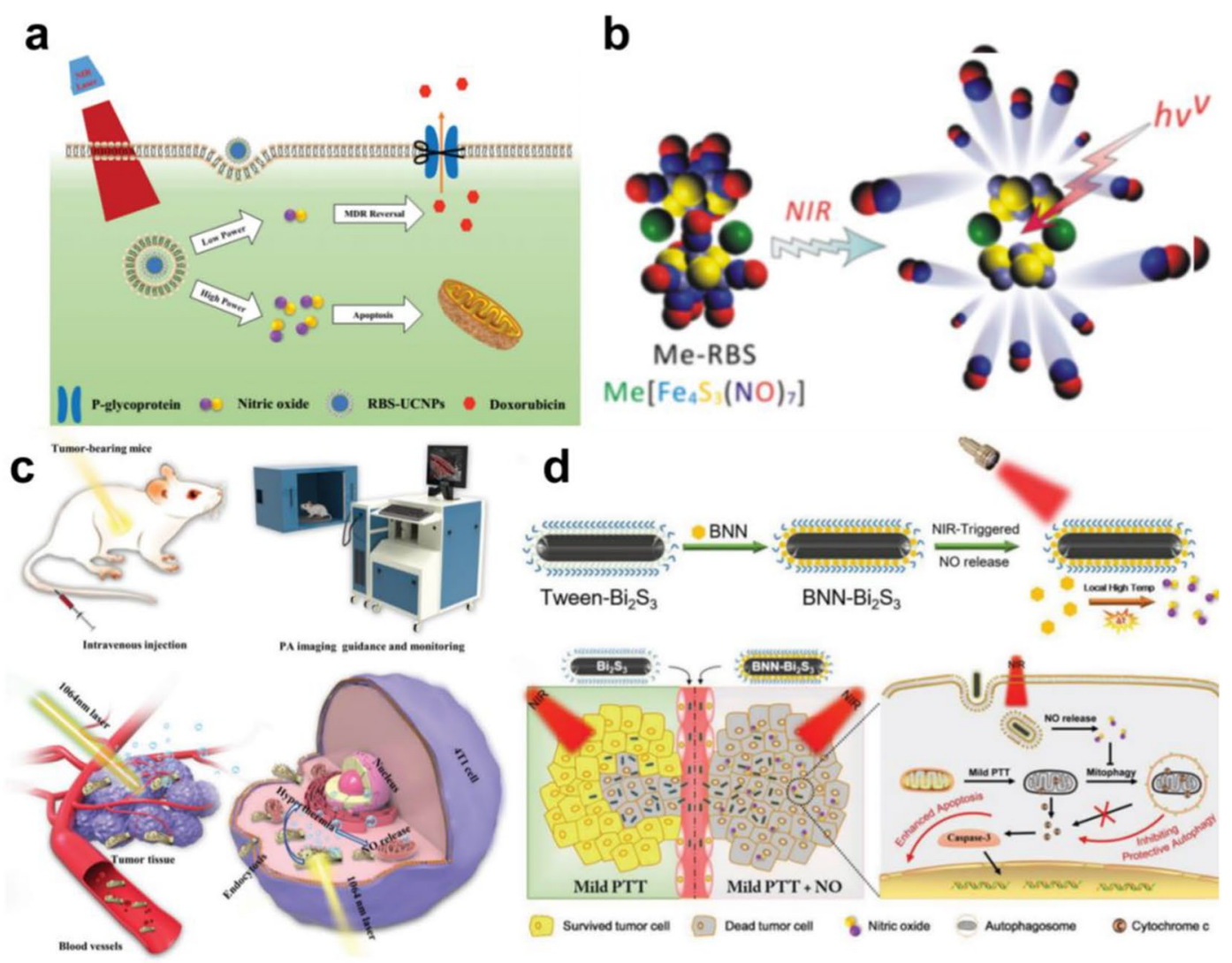

20 Survivod tumor coll Dead tumor cell
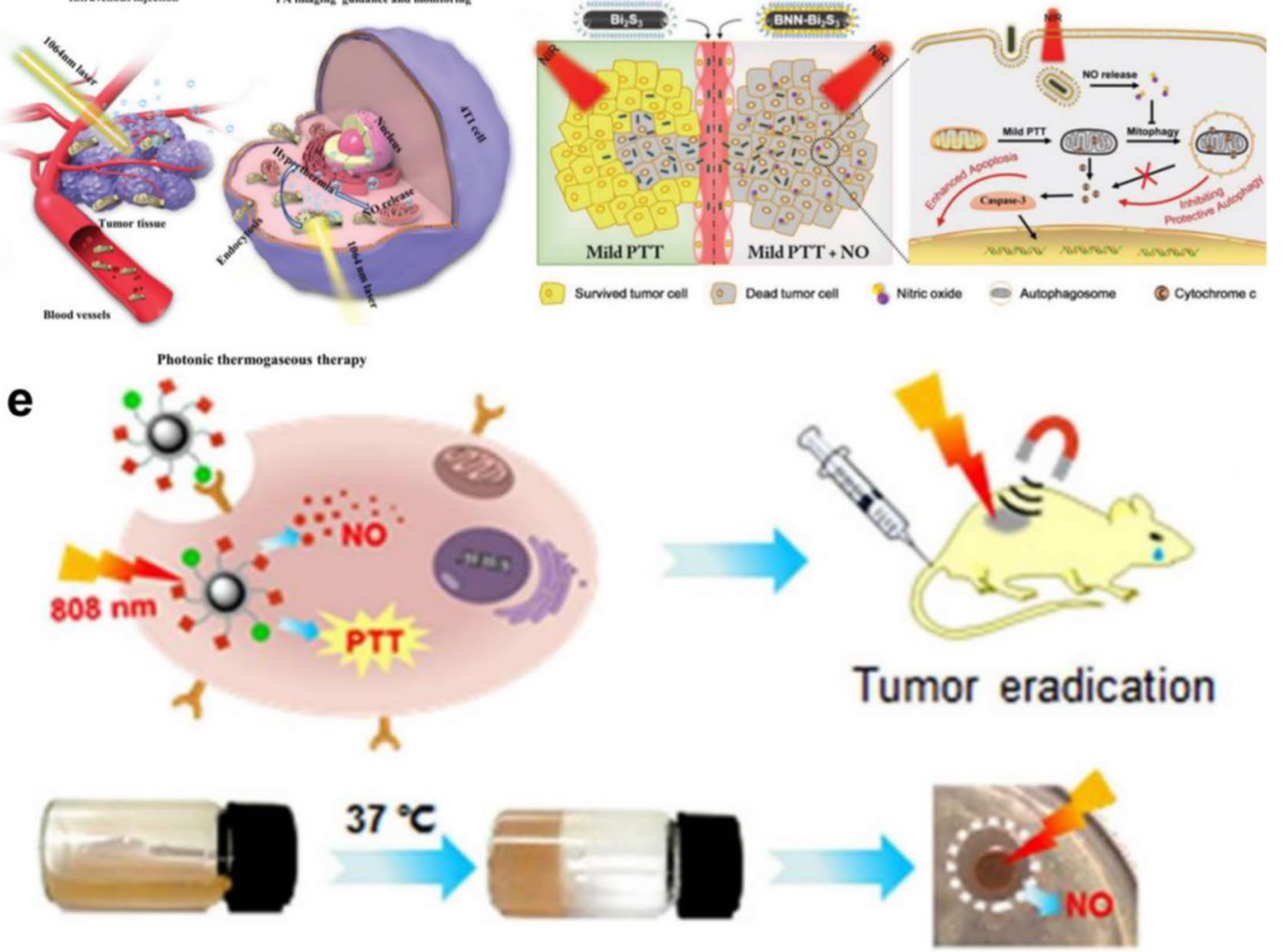

\section{Bacterial eradication}

Fig. 1 a Schematic illustration of 980-nm laser light-triggered on-demand NO release for dose-dependent therapeutic applications. Reproduced with permission from Ref [73]. Copyright 2015, Wiley-VCH. b Schematic illustration of the coordination-precipitation process of Me-RBS and NIR-responsive release of NO. Reproduced with permission from Ref [75]. Copyright 2017, American Chemical Society. c Schematic illustration of theranostic functions of $\mathrm{Nb}_{2} \mathrm{C}-\mathrm{MSN}$-SNO, including free delivery within blood vessel after intravenous injection, photothermal-triggered $\mathrm{NO}$ release, photonic thermogaseous therapy toward oncotherapy, and PAl guidance and monitoring. Reproduced with permission from Ref [76]. Copyright 2019, Wiley-VCH. d Schematic illustration of synthetic procedure and NIR-triggered NO release property of BNN-Bi $\mathrm{S}_{3}$, and synergistic mechanism of NO and mild PTT in cancer therapy. Reproduced with permission from Ref [77]. Copyright 2019, Wiley-VCH. e Schematic of the nanoplatform (1) for target-directed delivery of $\mathrm{NO}$ and production of PTT under $808 \mathrm{~nm}$ light irradiation, and schematic of the preparation of the CS-PVA/NO hydrogel and its antibacterial effect by NO under irradiation with $808 \mathrm{~nm}$ light. Reproduced with permission from Ref [78]. Copyright 2020, American Chemical Society 
polypeptide-polyoxyethylene drug-loaded micelles have been approved by the Food and Drug Administration (FDA) to enter clinical antitumor trials [132]. Therefore, Dong et al. designed an NIR-responsive drug-loaded peptide nanocomposite (PNOC-PDA/DOX) by coupling poly(L-cysteine $)_{20}$-poly(ethylene oxide $)_{45}(\mathrm{PC})$ with $\mathrm{S}$-nitroso(SNO) and embedding biomimetic dopamine (PDA) and DOX. Under $808 \mathrm{~nm}$ laser irradiation, PTT can induce the pyrolysis of S-NO to release NO. PNOCPDA/DOX exhibits $\mathrm{pH}$-responsive drug release. In the acidic tumor microenvironment, protonation of the amino group on DOX destroys $\pi-\pi$ stacking to trigger drug release. NO can also overcome the MDR of tumors, enhancing their chemosensitivity by significantly inhibiting the expression of P-gp (Fig. 2a) [80].

Sodium nitroprusside (SNP) is not only a commonly used drug in the treatment of hypertension but also an NO donor [74, 75]. Zhang et al. synthesized hollow mesoporous Prussian blue loaded with docetaxel (DTX@m-PB-NO) using SNPs. Under 808 nm laser irradiation, DTX@m-PB-NO can realize triple therapy with $\mathrm{NO}$ gas therapy, PTT and chemotherapy at the same time. In a mouse tumor model, DTX@m-PB-NO not only showed an obvious ability to kill tumors under NIR irradiation but also inhibited tumor lung metastasis. Picric acid staining was used to detect lung metastatic nodules. There were almost no lung metastatic nodules in the DTX@m-PB-NO + NIR group, while obvious lung metastatic nodules could be seen in the control groups (Fig. 2b) [81]. Recently, Fan et al. constructed semiconductor polymer nanoparticles (SPNs PFTDPP) by using the S-nitrosomercaptan group (SNAP) as a NO donor. Under the thermal energy produced by $808 \mathrm{~nm}$ laser radiation, SNAP can undergo thermal decomposition into NO. In addition, PFTDPP exhibits an obvious fluorescence signal in the NIR II region under $808 \mathrm{~nm}$ laser irradiation, enabling fluorescence imaging. Therefore, PFTDPP SPNs can use fluorescence imaging characteristics to guide NO gas therapy and PTT (Fig. 2c) [82].

\section{Photodynamic therapy-triggered NO prodrug}

In antineoplastic therapy, PDT can also be used to trigger the controlled release of NO, which could inhibit the expression of P-gp protein and improve the sensitivity of cancer cells to chemotherapeutic drugs [133, 134]. In addition, $\mathrm{NO}$ can directly or indirectly react with ROS to form highly active peroxynitrite $\left(\mathrm{ONOO}^{-}\right)$molecules, improving the efficacy of gas therapy and PDT $[133,135]$. According to many recent studies, lysosomes are closely related to the programmed death of cancer cells [136]. Therefore, Liu et al. developed a novel multifunctional NO delivery platform for cancer cell lysosome targeting. The nanoplatform can selectively target cancer cells

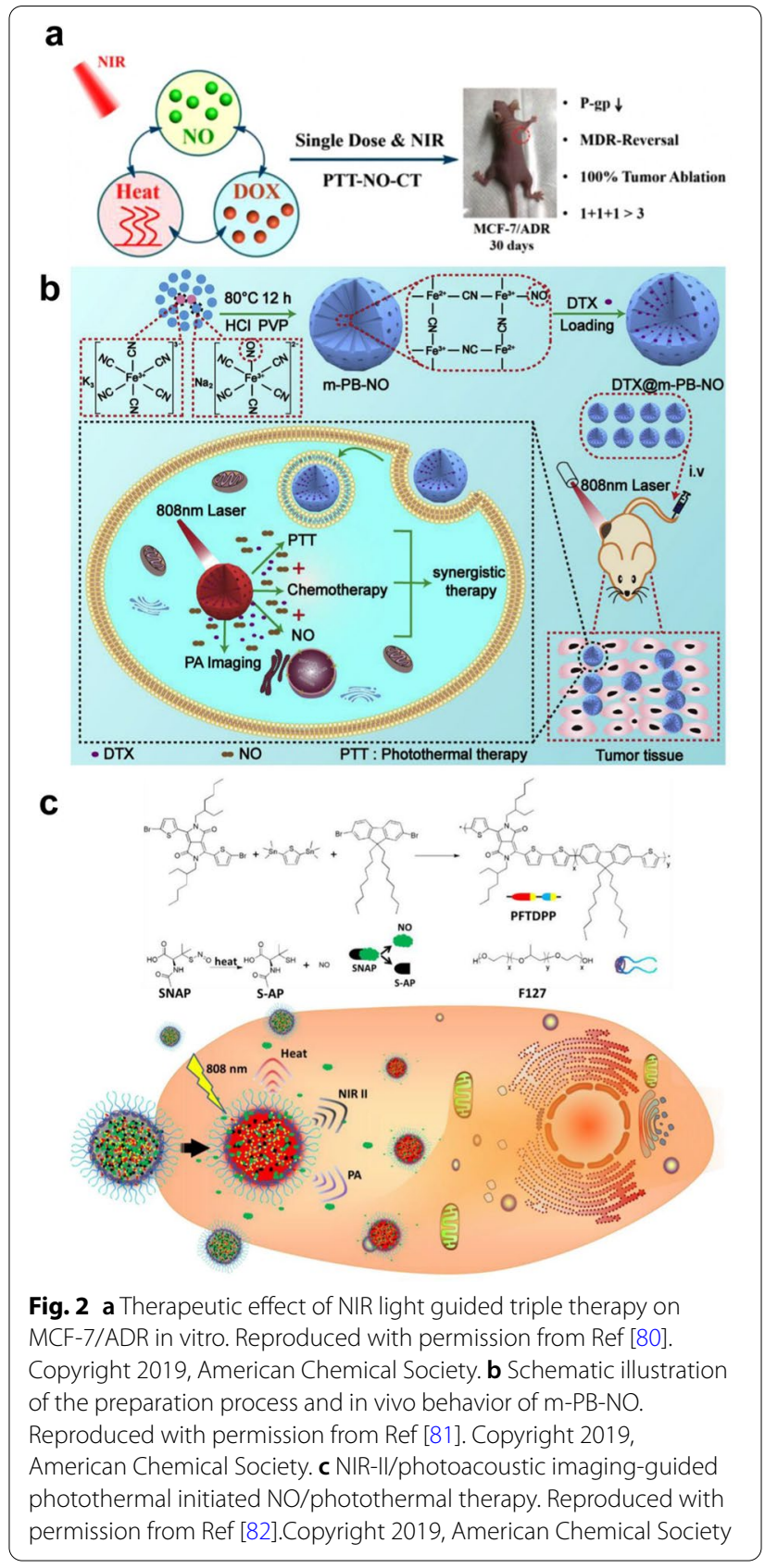

overexpressing folate receptor (FR) and enrich in the lysosomes of cancer cells. Under $808 \mathrm{~nm}$ laser irradiation, nanoparticles can undergo phototriggered electron and energy transfer in lysosomes. This process will stimulate the release of $\mathrm{NO}$ and ROS from the NO donor and surrounding $\mathrm{O}_{2}$, resulting in lysosome damage and promoting the programmed death of cancer cells [83]. However, once the nanoparticles enter the human body, they will be easily cleaned by the human immune system and captured by capillaries, which would decrease the drug 
concentration at the tumor site, reducing the therapeutic effects [137]. To overcome this problem, Zhang et al. prepared a porous coordination network (PCN) containing the NO donor L-arginine (L-Arg) inside a cancer cell membrane. The biomimetic multifunctional nanosystem (L-Arg@PCn@Mem) exhibits good homologous targeting to tumor tissues, which can avoid immune cleaning and take advantage of EPR at the tumor site. In addition, once PCN is irradiated by a $660 \mathrm{~nm}$ laser, it will produce a large number of free radicals, which can convert L-Arg into NO. The ROS-stimulated production of NO can enhance the effect of PDT under hypoxia to realize combined gas therapy and PDT (Fig. 3a) [84].

Diketopyrrolopyrrole (DPP) derivatives are efficient photosensitizers that have the advantages of NIR absorption, high light stability and thermal stability [138-140]. Recently, Dong et al. designed $\mathrm{pH}$-sensitive DPP nanoparticles (DPPNF) loaded with NO photodonors (4-nitro3-trifluoromethylaniline, $\mathrm{NF}$ ) and $\mathrm{pH}$-sensitive groups (dimethylaminophenyl). DPPNF can be activated in the acidic environment of lysosomes, enhancing the ROS production and photothermal effects. Under $660 \mathrm{~nm}$ NIR light irradiation, NF can achieve the controllable release of NO under light/dark conditions, which induces lysosomal damage to enhance the efficacy of PDT, leading to tumor cell apoptosis. It shows excellent tumor lethality in gas therapy, PTT and PDT (Fig. 3b) [85]. In another work, Zhang et al. developed a complex liposome nanosystem that can sequentially release NO and DOX. Under $808 \mathrm{~nm}$ laser irradiation, nanoparticles with Au-NRs as the core undergo resonance energy transfer (RET) to produce a large amount of ROS. L-Arg can be converted to NO by NO synthetase with ROS-induced activity. When liposomes embedded with hydrophobic o-phenylenediamine lipids encounter NO gas molecules, the o-phenylenediamine lipids can change from hydrophobic to hydrophilic. This process destroys the phospholipid bilayer of liposomes and eventually releases DOX. At the same time, NO can inhibit the expression of P-gp, creating a favorable microenvironment for the later release of DOX accumulation (Fig. 3c) [86].

\section{NIR light-triggered CO prodrug}

For a long time, $\mathrm{CO}$ has been considered a toxic substance. When it enters the blood, it reduces the oxygen-carrying capacity of hemoglobin, which can lead to permanent damage and even death [141]. However, recent studies have found that endogenous $\mathrm{CO}$ produced by heme oxygenase (HMOX) has a protective effect against tissue and cell damage [142, 143]. Endogenous $\mathrm{CO}$ is also a second messenger that regulates the cellular signaling pathway and participates in various physiological and pathological responses in the human

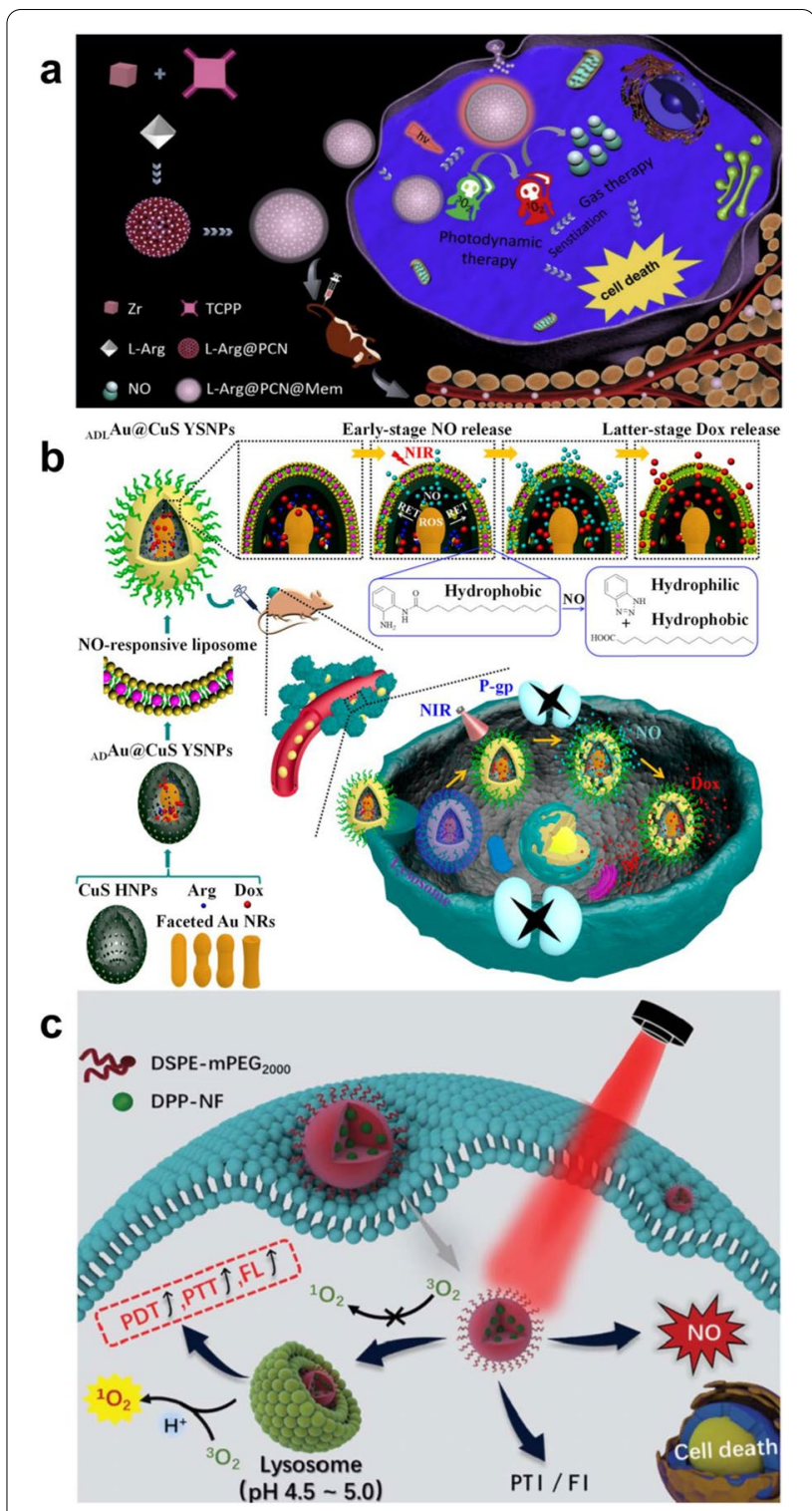

Fig.3 a Schematic illustration of L-Arg@PCN@Mem preparation and lethal mechanism of gas therapy and sensitized photodynamic therapy against tumor cells. Reproduced with permission from Ref [84]. Copyright 2018, Elsevier Ltd. b Illustrating the NO and Dox programmable release and MDR cancer therapy of ${ }_{A D L} \mathrm{Au}_{2} @ \mathrm{CuS}$ YSNPs. Reproduced with permission from Ref [85]. Copyright 2018, American Chemical Society. c Schematic illustration of pH-responsive DPP-NF NPs for PTI and FI guided PDT/PTT/GT synergistic cancer therapy. Reproduced with permission from Ref [86]. Copyright 2019, The Royal Society of Chemistry

body [141]. It has significant therapeutic potential in the treatment of many related diseases, including cerebral infarction, organ transplantation, arteriosclerosis, stroke and cancer [13, 144-148]. CO can promote the proliferation, metabolism and metastasis of tumor cells at low levels, while it can induce tumor cell death by interfering 
with mitochondrial respiration and increasing ROS at high levels, which lays a foundation for the treatment of tumors with CO $[13,144]$. Therefore, the realization of a controlled-release $\mathrm{CO}$ prodrug is very important to improve the effectiveness of $\mathrm{CO}$ gas therapy and reduce the risk of $\mathrm{CO}$ poisoning. It is urgent to develop a nanogas delivery system that can target diseased tissues and control the release of CO gas [13].

\section{Photothermal therapy-triggered $\mathrm{CO}$ prodrug}

To reduce the early leakage of $\mathrm{CO}$ in blood circulation and increase the accumulation of $\mathrm{CO}$ in tumor tissues, the use of NIR to stimulate CO prodrug nanoplatforms for on-demand release has attracted widespread attention in recent years. Prussian blue (PB) has been approved by the FDA in the United States as an antidote for heavy metal poisoning and has good biocompatibility and safety [149]. Therefore, Yeh et al. allowed polyethylene glycol carbonyl iron to react with mesoporous Prussian blue as the carrier to obtain a $\mathrm{CO}$ nanogas prodrug (m-PB-CO). Under $808 \mathrm{~nm}$ laser irradiation, the photothermal effect can trigger $\mathrm{m}-\mathrm{PB}-\mathrm{CO}$ to release $\mathrm{CO}$. In contrast, in the absence of laser irradiation, $\mathrm{m}-\mathrm{PB}-\mathrm{CO}$ shows no $\mathrm{CO}$ release within 7 days, with high biological safety. In addition, $\mathrm{m}-\mathrm{PB}-\mathrm{CO}$ enables ultrasonic imaging under laser irradiation. In the mouse tumor model, the ultrasonic echo signal in the tumor was monitored by on/off pulsing of the laser. When $\mathrm{m}-\mathrm{PB}-\mathrm{CO}$ was injected into the tumor, compared with the group without laser irradiation, the ultrasonic signal of the tumor was significantly enhanced due to the release of $\mathrm{CO}$ after $5 \mathrm{~min}$ of $808 \mathrm{~nm}$ laser irradiation (Fig. 4a) [87]. Although PB nanoparticles have high biological safety, their photothermal conversion rate is not high. Palladium-loaded nanotablets (PdNS) have been widely used in NIR photothermal therapy because of their excellent photothermal conversion rate [150]. Wei et al. prepared ultrathin PdNS-CO nanocrystals using $\mathrm{CO}$ as a reducing agent. In addition, the photothermal conversion rate of PdNS-CO can be as high as 40\%. After $808 \mathrm{~nm}$ laser irradiation, an excellent photothermal effect can trigger PdNS-CO to release CO, which can enrich PdNS-CO in tumors and enhance its antitumor effect by EPR [88].

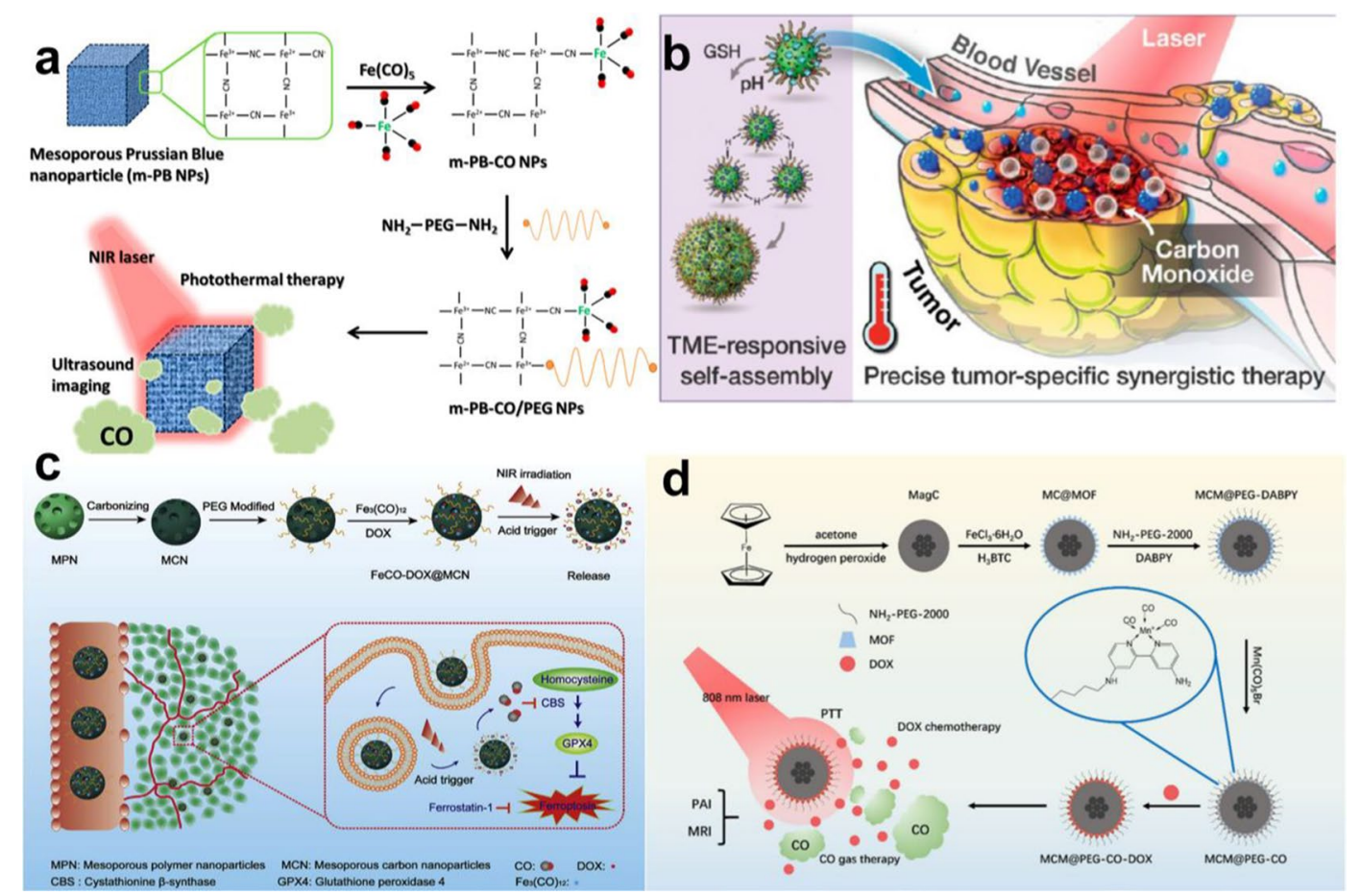

Fig. 4 a Synthetic Strategy for NIR-Responsive m-PB-CO/PEG NPs Applied for CO and Photothermal Therapy and US Imaging. Reproduced with permission from Ref [87]. Copyright 2016, American Chemical Society. b Schematic Illustration of the $\mathrm{Mn}_{2}(\mathrm{CO}) 10$-Loaded and POM Surface-Modifified Hollow Mesoporous Organosilica Nanoplatform, HMOPM-CO, for Tumor Microenvironment (TME)-Responsive Self-Assembly and Precise Synergistic Therapy. Reproduced with permission from Ref [89]. Copyright 2018, American Chemical Society. c Schematic illustration of multifunctional nanoplatform for photoacoustic imaging-guided combined therapy enhanced by CO induced ferroptosis. Reproduced with permission from Ref [90]. Copyright 2019, Elsevier Ltd. d The synthetic workfflow of MCM@PEG-CO-DOX for NIR light-responded CO-DOX combination therapy of tumor with dual-mode imaging. Reproduced with permission from Ref [92]. Copyright 2019, Elsevier Ltd 
Hollow mesoporous organosilicon nanoparticles (HMONs) have wide application prospects in the biomedical field because of their large specific surface area, uniform mesoporous structure, high chemical stability and controllable surface modification [151]. Chen et al. used a special "ammonia-assisted hot water etching" method to load $\mathrm{Mo}(\mathrm{VI})$-based polyoxometalate (POM) and the CO-release molecule $\mathrm{Mn}_{2}(\mathrm{CO})_{10}$ into HMONs. In the acidic tumor microenvironment, POM protonates and leads to the accumulation of HMONs in the tumor, enhancing the EPR effect of the tumor. In addition, the reductive tumor microenvironment will induce the reduction of $\mathrm{Mo}(\mathrm{VI})$ to $\mathrm{Mo}(\mathrm{V})$, which has stronger NIR light absorption. Therefore, under $808 \mathrm{~nm}$ irradiation, PTT can further trigger the thermal decomposition of $\mathrm{Mn}_{2}(\mathrm{CO})_{10}$ and release $\mathrm{CO}$, which acts synergistically with PTT (Fig. 4b) [89]. Compared with HMONs, mesoporous carbon nanoparticles (MCNs) have stronger absorbance, higher photothermal conversion efficiency and lower in vivo toxicity in the NIR region [152]. Yang et al. constructed an MCN nanoplatform (FeCO-DOX@ $\mathrm{MCN}$ ) loaded with DOX and triiron dodecacarbonyl (FeCO), which realized combined gas therapy and PTT. FeCO-DOX@MCN nanoparticles exhibit pH-dependent drug release behavior that can release more DOX in the acidic tumor microenvironment. Under $808 \mathrm{~nm}$ laser irradiation, the excellent photothermal conversion rate of FeCO-DOX@MCN can cause the thermal decomposition of $\mathrm{FeCO}$ to release $\mathrm{CO}$. At the same time, $\mathrm{CO}$ can inhibit the expression of cystathionine $\beta$ synthase (CBS) and glutathione peroxidase 4 (Gpx4), increasing the sensitivity of cancer cells to DOX by enhancing the effect of ferroptosis (Fig. 4c) [90].

As an excellent type of nanocarrier for drug delivery systems, metal organic frameworks (MOFs) have been widely used in a variety of drug carriers because of their low toxicity, high drug loading rate and high targeting [153]. Shen et al. formed MCM@PEG-CO-DOX nanoparticles by coloading DOX and $\mathrm{CO}$ prodrugs into an MOF and embedding polyethylene glycol magnetic carbon nanoparticles. Under $808 \mathrm{~nm}$ laser radiation, MCM@PEG-CO-DOX converts light energy into thermal energy, triggering $\mathrm{CO}$ and DOX release. In addition, MCM@PEG-CO-DOX can target the mitochondria of cancer cells to release $\mathrm{CO}$, which can quickly cause mitochondrial damage and enhance the sensitivity of cancer cells to DOX, leading to cancer cell apoptosis. This will enhance the sensitivity of cancer cells to DOX, leading to apoptosis of cancer cells. In addition, MCM@PEG-CODOX can enable magnetic resonance imaging (MRI) and photoacoustic imaging (PAI) of tumors. Compared with non-intratumoral injection of the drug, intratumoral injection in mice resulted in T2 signal intensity at the tumor site of the mice with a lower signal area, while the PAI signal intensity showed a higher signal intensity [91]. Zhang et al. modified the surface of defective tungsten oxide $\left(\mathrm{WO}_{3}\right)$ nanosheets (DW NSs) with bicarbonate (BC) by ferric ion-mediated coordination and further modified it with polyethylene glycol (PEG) to fabricate PEG@DW/BC nanosheets. Under $808 \mathrm{~nm}$ laser irradiation, PEG@DW/BC, producing a photothermal effect, can decompose $\mathrm{BC}$ to release $\mathrm{CO}_{2}$ and act as a $\mathrm{CO}$ photocatalyst to convert $\mathrm{CO}_{2}$ into $\mathrm{CO}$. In addition, $\mathrm{CO}$ produced by PEG@DW/BC significantly inhibits the proinflammatory cytokines tumor necrosis factor- $\alpha$ (TNF- $\alpha$ ) and interleukin-6 (IL-6), eliminating the inflammatory response produced by PTT (Fig. 4d) [92].

\section{Photodynamic therapy-triggered CO prodrug}

ROS induced by NIR light not only can be activated by heat but also can trigger the release of $\mathrm{CO}$ [154]. The curative effect of PDT is mainly because the photosensitizer can produce a large amount of ROS under NIR light, which can induce the programmed death of cancer cells [155]. Although $\mathrm{H}_{2} \mathrm{O}_{2}$ produced by the PDT process was found to be involved in cancer cell apoptosis, long-term accumulation of high concentrations would lead to tumor recurrence and metastasis [156]. Therefore, $\mathrm{Gu}$ et al. reported a controlled CO-release system (CORM@G3DSP-CE6) driven by PDT that integrates the photosensitizer e6 chloride (Ce6) and the $\mathrm{H}_{2} \mathrm{O}_{2}$-sensitive CO-release molecule CORM-401 into a polypeptide dendrimer nanogel. Under laser irradiation, CORM@ G3DSP-CE6 accumulates in the tumor, producing a large amount of $\mathrm{H}_{2} \mathrm{O}_{2}$, which could weaken the Mn-CO backbond in CORM-401 to release $\mathrm{CO}$ while being largely consumed. However, this process does not affect the production of ${ }^{1} \mathrm{O}_{2}$, which not only retains the anticancer effect of PDT but also reduces the side effects of PDT. This will improve the anticancer effect [93]. There has been widespread interest in interference with cancer metabolism as an antitumor mechanism [157]. For example, starvation therapy can block tumor ATP supply by inhibiting the oxidative phosphorylation pathway, which can cause cancer cell necrosis [158]. Dong et al. designed a nanometallo-organic skeleton (NMOF) embedded with a photosensitizer (21-BODIPY) and CO prodrug $(\mathrm{MnCO})$, which can achieve the synergistic effect of PDT and starvation therapy. Under NIR irradiation, the PDT process produces a large amount of ROS to promote the release of $\mathrm{CO}$ from MnCO. At the same time, PDT and $\mathrm{CO}$ gas therapy can cause mitochondrial damage and inhibit aerobic glycolysis, which blocks the energy supply of cancer cells, achieving effective combined treatment of cancer [94]. 
Currently, some chemotherapeutic drugs can be fully activated in a specific tumor microenvironment, such as in the presence of overexpressed enzymes, overproduced ROS or hypoxia [159]. Yin et al. developed an NIR light-triggered CO release system, which consists of mesoporous Prussian blue nanoparticles (PB NPs) as a photosensitizer, pentacarbonyl iron $\left(\mathrm{Fe}(\mathrm{CO})_{5}\right)$ as a $\mathrm{CO}$ donor and the bioreductive anticancer drug Tirapazamine (TPZ). Under $808 \mathrm{~nm}$ laser irradiation, the nanoparticles produce a large amount of ROS, leading to the decomposition of $\mathrm{Fe}(\mathrm{CO})_{5}$ and the release of a large amount of $\mathrm{CO}$, which can cause mitochondrial damage and aggravate the hypoxic environment in the tumor by depolarizing the mitochondrial membrane. TPZ can be activated in the deep hypoxic tumor microenvironment, which aggravates the apoptosis of cancer cells and achieves a strong antitumor effect (Fig. 5a).[95] Currently, chemotherapy is still the main treatment for cancer in the clinic, but the MDR of cancer is a great obstacle to the efficacy of chemotherapy [131]. Yin et al. first used a $\mathrm{CO}$ nanodrug delivery system to overcome the MDR of tumors. $\mathrm{Fe}(\mathrm{CO})_{5}$ and DOX were coupled to mesoporous Prussian blue nanoparticles (PB NPs) to construct an NIR-responsive CO release system. Under $808 \mathrm{~nm}$ laser irradiation, the photothermal effect can cleave the $\mathrm{Fe}-\mathrm{CO}$ bond to release $\mathrm{CO}$, inducing mitochondrial damage. This process leads to the inhibition of APT-dependent drug efflux, which greatly increases the accumulation of DOX in tumor cells, overcoming the MDR of tumors. In addition, the large amount of ROS released during PDT can upregulate the expression of the proapoptotic protein caspase 3 and induce apoptosis [96].

In recent years, nanocoordination polymers (NCPs) based on the combination of metal ions and organic compounds have attracted wide attention because of their high drug loading and high biosafety [160]. For example, NCPs containing copper ions have been used in antitumor therapy because of their excellent Fenton-like response in the tumor microenvironment [161]. Therefore, Wang et al. reported a GSH and NIR photoresponsive $\mathrm{CO}$ nano-prodrug composed of a $\mathrm{CO}$ donor (Fle) and $\mathrm{Cu}^{2+}$. The high concentration of GSH in the tumor microenvironment cleaves $\mathrm{NCu}$-FleCP into smaller Fle and $\mathrm{Cu}^{2+}$, which enhances the drug uptake of cancer cells. In addition, high concentrations of $\mathrm{H}_{2} \mathrm{O}_{2}$ in the tumor microenvironment will react with $\mathrm{Cu}^{2+}$ to produce Fenton-like reactions to release a large amount of highly toxic. $\mathrm{OH}$. Under irradiation with an $808 \mathrm{~nm}$ laser, the $\mathrm{C}-\mathrm{C}$ bond of Fle is cleaved to release $\mathrm{CO}$, causing damage to mitochondria. $\mathrm{CO}$ and. $\mathrm{OH}$ produced in situ can significantly promote the apoptosis of cancer cells, resulting in a significant synergistic anticancer effect [97]. Carbonyl compound complexes are easily oxidized under the physiological conditions of the human body, which inevitably leads to CO leakage [13]. Therefore, Zhang et al. encapsulated $\mathrm{Fe}(\mathrm{CO})_{5}$ in a $\mathrm{Au}$ nanocage cavity under anaerobic conditions and then formed iron oxide on the surface of Au nanocages under aerobic conditions, which effectively prevented $\mathrm{CO}$ leakage and oxidation, ensuring the stability and biocompatibility of the nanomaterials. After laser irradiation, $\mathrm{Fe}(\mathrm{CO})_{5}$ is thermally decomposed into $\mathrm{CO}$ and Fe. At this time, in the acidic tumor microenvironment, the iron oxide wrapped on the surface of the $\mathrm{Au}$ nanocage is decomposed by acid, releasing $\mathrm{CO}$ and Fe into the tumor in situ. $\mathrm{CO}$ gas can produce ROS by interfering with the mitochondrial respiratory chain, resulting in mitochondrial autophagy, which induces the accumulation of iron and iron oxide in lysosomes. The Fenton reaction of iron and iron oxide in acidic environments produces a large amount of hydrogen peroxide, which destroys lysosomes and accelerates the death of cancer cells (Fig. 5b) [98].

\section{NIR light-triggered $\mathrm{H}_{2} \mathrm{~S}$ prodrug}

In the past, hydrogen sulfide $\left(\mathrm{H}_{2} \mathrm{~S}\right)$ was considered to be a highly toxic gas. In fact, it is also an endogenous cellular signal mediator that can transmit biological information between cells in physiology or pathology [11]. Therefore, endogenous $\mathrm{H}_{2} \mathrm{~S}$ is considered to be the third gas transmitter in addition to $\mathrm{NO}$ and $\mathrm{CO}[10,162,163] . \mathrm{H}_{2} \mathrm{~S}$ signaling molecules show great potential in the treatment of many diseases, such as inflammation, diabetes and cancer [164-167]. It has been reported that a high concentration of $\mathrm{H}_{2} \mathrm{~S}$ can produce a large amount of ROS, causing mitochondrial damage and inducing tumor cell apoptosis [167-169]. In recent years, the application of hydrogen sulfide in the medical field has aroused widespread interest, but controlling the release of $\mathrm{H}_{2} \mathrm{~S}$ gas in time and space is still a difficult challenge. NIR-mediated PTT and PDT can stimulate $\mathrm{H}_{2} \mathrm{~S}$ donors to release $\mathrm{H}_{2} \mathrm{~S}$, which has the unique advantages of being simple, noninvasive, safe and low in side effects [170-174]. Therefore, suitable photosensitizers are particularly important to control the release of $\mathrm{H}_{2} \mathrm{~S}$. At present, some photosensitizers have been used in the treatment of cancer, such as gold nanoparticles [175-180], carbon materials [181183], copper sulfide nanoparticles [184-189], and organic dyes [190-195].

\section{Photothermal therapy-triggered $\mathrm{H}_{2} \mathrm{~S}$ prodrug}

In recent years, UCNPs have attracted widespread interest in the fields of biological imaging and antitumor activity because of their unique optical properties [167]. UCNPs can convert NIR light into UV or visible light, which enables their use in the biomedical field as carriers for the transmission or release of NIR light [196]. Liu 


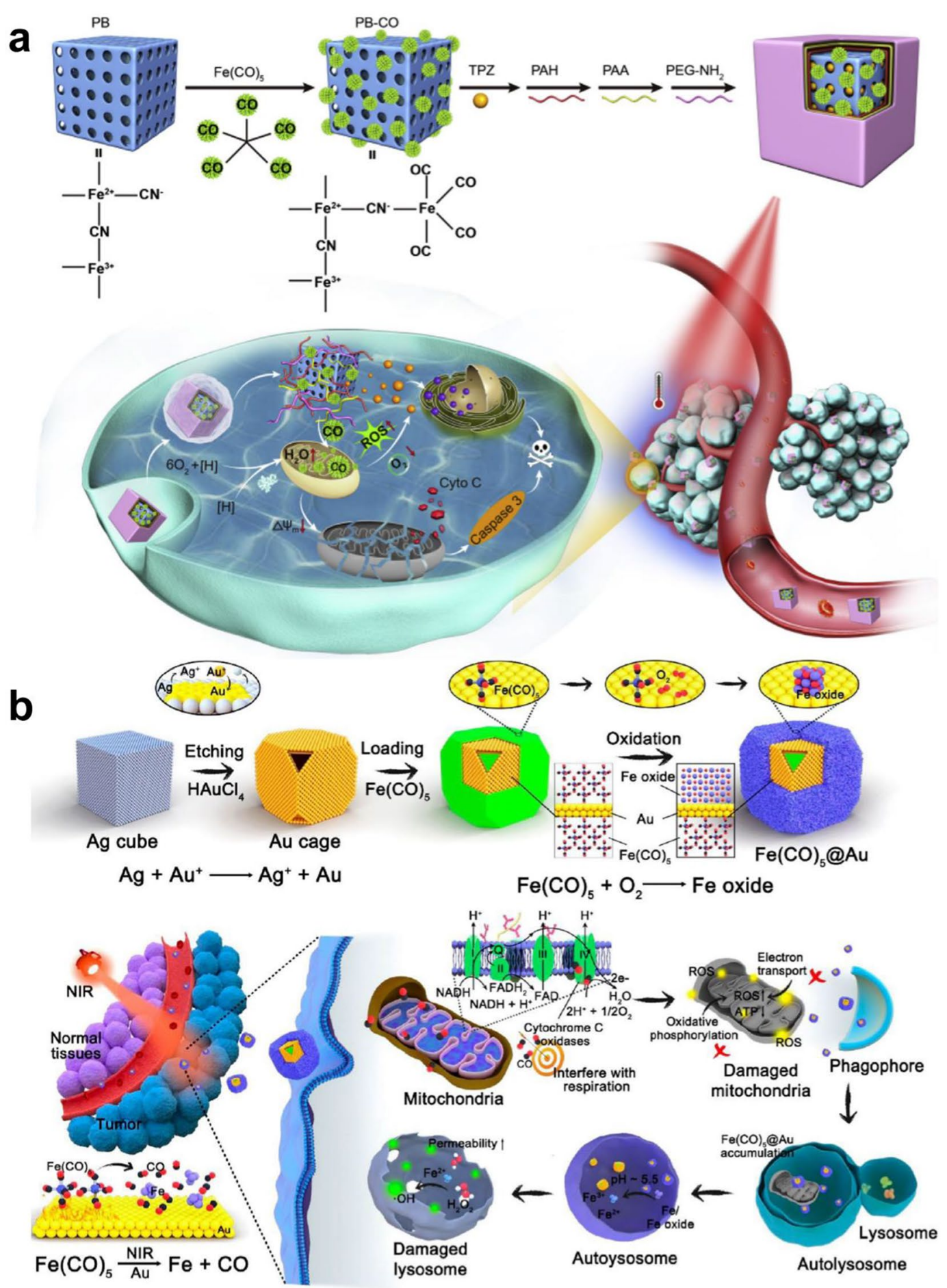

Fig. 5 a Schematic illustration of PPPPB-CO-TPZ NPs with enhanced bioreductive chemotherapy and CO-mediated pro-apoptotic gas therapy. Reproduced with permission from Ref [95]. Copyright 2019, Elsevier Ltd. b Design of a controlled CO delivery nanomaterial for improving cancer therapy. Reproduced with permission from Ref [98]. Copyright 2020, American Chemical Society 
et al. synthesized a new $\mathrm{H}_{2} \mathrm{~S}$ donor (SP) for the first time and loaded it on the surface of UCNPs by hydrophobic interactions. Under $980 \mathrm{~nm}$ laser irradiation, the UV converted from NIR by UCNPs cleaves SP to gem-dithiols by luminescence resonance energy transfer (LRET). PTT can promote the thermal decomposition of gem-dithiols to release $\mathrm{H}_{2} \mathrm{~S}$ gas. In addition, UCNPs can emit strong NIR fluorescence after NIR irradiation. SP-UCNPs were injected into mice and irradiated with $980 \mathrm{~nm}$ NIR light. The IVIS imaging system can track SP-UCNPs in vivo, which can regulate the targeted release of $\mathrm{H}_{2} \mathrm{~S}$ (Fig. 6a) [99].

Reduced graphene oxide (rGO) has an excellent photothermal conversion rate for NIR and is a good carrier for photothermal therapy [197]. Dithiocarbamate (DTC) is the donor of $\mathrm{H}_{2} \mathrm{~S}$ and can be pyrolyzed to $\mathrm{H}_{2} \mathrm{~S}$ at high temperature [198]. Therefore, Liu et al. developed an NIR-photoresponsive $\mathrm{H}_{2} \mathrm{~S}$ gas generation nanoplatform (rGO-PEI-DTC) with a high drug loading rate by the electrostatic adsorption of positively charged DTC and negatively charged rGO. Under irradiation with NIR

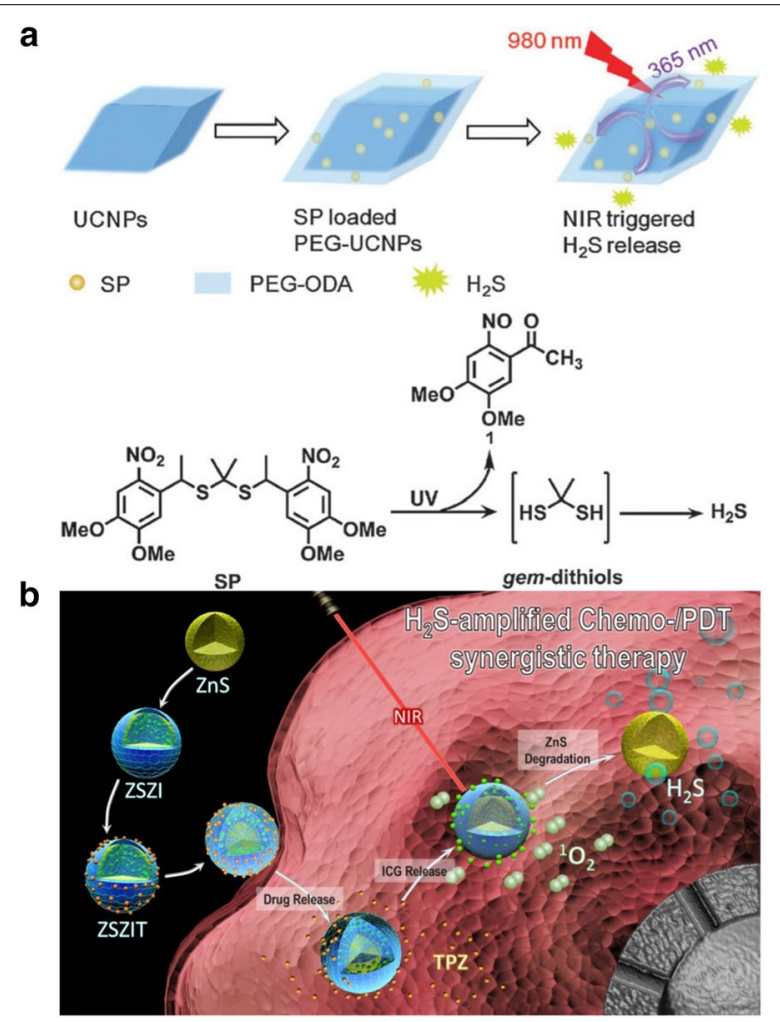

Fig. 6 a Construction of SP-loaded PEG-UCNPs platform for NIR triggered $\mathrm{H}_{2} \mathrm{~S}$ release. Reproduced with permission from Ref [99]. Copyright 2015, The Royal Society of Chemistry. b Schematic illustration of ZSZIT as a $\mathrm{H}_{2} \mathrm{~S}$-sensitized PDT/chemotherapeutic synergistic nanoplatform. Reproduced with permission from Ref [102]. Copyright 2020, Ivyspring International Publisher light, light energy is converted into thermal energy based on the photothermal effect of rGO, and a large amount of $\mathrm{H}_{2} \mathrm{~S}$ is released due to the thermal degradation of DTC. In the cell experiment, the rGO-PEI-DTC + NIR group showed higher cytotoxicity than the rGO and PEI-DTC groups, thus showing inhibition of the proliferation of cancer cells [100, 199].

Diallyl trisulfide (DATS), as a donor of $\mathrm{H}_{2} \mathrm{~S}$, can be decomposed into $\mathrm{H}_{2} \mathrm{~S}$ by reductive $\mathrm{GSH}$, which has good biological safety and strong cytotoxicity to cancer cells [200]. Zhang et al. constructed a complex gas-producing nanoplatform $\left(\mathrm{Bi}_{2} \mathrm{~S}_{3}-\mathrm{Ag}_{2} \mathrm{~S}\right.$-DATS@BSA-N $\left.{ }_{3} \mathrm{NYs}\right)$ that responds to NIR light stimulation. In a tumor microenvironment rich in reductive GSH, DATS can be decomposed by GSH to release $\mathrm{H}_{2} \mathrm{~S}$. At the same time, the $\mathrm{H}_{2} \mathrm{~S}$ released by the tumor in situ can reduce the surface $-\mathrm{N}_{3}$ $(-)$ to $-\mathrm{NH}_{2}(+)$, resulting in the adsorption of negatively charged BSA and increasing the size of NYs, which effectively enhances the enrichment of nanodrugs in the tumor site. Under $808 \mathrm{~nm}$ laser irradiation, the photothermal conversion rate of the nanoparticles was as high as $31.6 \%$, which indicates an excellent photothermal effect. In addition, $\mathrm{Bi}_{2} \mathrm{~S}_{3}-\mathrm{Ag}_{2} \mathrm{~S}$-DATS@BSA- $\mathrm{N}_{3} \mathrm{NYs}$ were injected into mice through the tail vein, and NIR-II fluorescence and PA imaging were performed. After $6 \mathrm{~h}$, the NIR-II fluorescence and PA signal of the tumor were significantly higher than those of the surrounding normal tissue. Therefore, NIR-II/PA dual-mode imaging-guided PTT and GT provides a promising method for effective antitumor therapy [101].

\section{Photodynamic therapy-triggered $\mathrm{H}_{2} \mathrm{~S}$ prodrug}

PDT can stimulate $\mathrm{H}_{2} \mathrm{~S}$ gas for use in antitumor therapy. TPZ is a hypoxia-activated anticancer drug that is highly toxic to cancer cells in the hypoxic tumor microenvironment but has little effect on cells with normal oxygen concentrations [201]. High expression of catalase (CAT), which is overexpressed in the tumor microenvironment, can convert $\mathrm{H}_{2} \mathrm{O}_{2}$ into oxygen, relieving hypoxia and weaking the anticancer effect of TPZ [202]. However, $\mathrm{H}_{2} \mathrm{~S}$ can inhibit the expression of CAT [203]. Han and others have developed a $\mathrm{H}_{2} \mathrm{~S}$ nanogas production platform (ZSZIT) composed of $\mathrm{ZnS}$ nanoparticles coated with zeolitic imidazolate framework-8 (ZIF-8) and combined with indocyanine green (ICG) and TPZ. In the acidic tumor microenvironment, the shell of ZIF-8 collapses due to protonation, releasing ICG and TPZ. Under NIR radiation at $808 \mathrm{~nm}$, ICG can induce PDT to produce ROS, which consume a large amount of oxygen at the tumor site, aggravating hypoxia in the tumor microenvironment. More importantly, $\mathrm{ZnS}$ can be degraded in situ to form $\mathrm{H}_{2} \mathrm{~S}$ gas in the tumor. $\mathrm{H}_{2} \mathrm{~S}$ can not only kill cancer cells but also downregulate the expression of CAT. This 
process aggravates the anoxic environment of the tumor tissue by blocking the transformation of $\mathrm{H}_{2} \mathrm{O}_{2}$ to $\mathrm{O}_{2}$ and activating and enhancing the cytotoxicity of TPZ. Therefore, due to the synergistic effects of PDT, $\mathrm{H}_{2} \mathrm{~S}$ and TPZ, ZSZIT has obvious antitumor effects in vivo and in vitro, indicating great potential in cancer treatment (Fig. 6b) [102].

\section{NIR light-triggered $\mathrm{H}_{\mathbf{2}}$ prodrug}

Gas therapy, a relatively new treatment method, mainly uses gas molecules $\left(\mathrm{NO}, \mathrm{CO}, \mathrm{H}_{2} \mathrm{~S}, \mathrm{H}_{2}\right.$ and $\mathrm{SO}_{2}$ ) to treat various diseases [204, 205]. Among them, $\mathrm{H}_{2}$ has higher biosafety than other gases, which has attracted increasing attention. In 1975, Dole et al. found that high concentrations of $\mathrm{H}_{2}$ can be used to treat skin cancer [206]. In 2007, $\mathrm{H}_{2}$ was proven to be able to scavenge harmful free radicals such as hydroxyl $(\cdot \mathrm{OH})$ and peroxynitrite $\left(\mathrm{ONOO}^{-}\right)$, thereby reducing inflammation or ischemiareperfusion damage [14]. Since then, a series of studies have shown that $\mathrm{H}_{2}$ has a significant therapeutic effect on a variety of diseases, including cancer, diabetes and neurodegeneration [14, 207, 208]. Unlike other therapeutic gas transmitters, hydrogen has no risk of poisoning even at high concentrations. However, the solubility of hydrogen is low, and it can diffuse arbitrarily in the body; as a result, directly inhaling hydrogen or injecting/drinking hydrogen-rich water is not an easy method to reach and accumulate a large number of hydrogen molecules in deep lesions [209]. Therefore, how to achieve hydrogen targeting and controllable and continuous hydrogen release at the target site through nanosystems is the main challenge at present.

\section{Photothermal therapy-triggered $\mathrm{H}_{2}$ prodrug}

Hydrogen is a flammable and explosive gas but has been regarded as biologically inert for a long time. However, a large number of recent studies have shown that in the physiological environment, hydrogen is an endogenous signaling molecule with good biosafety and is considered to be a reductive homeostatic regulator [210]. It has shown certain effects on many diseases related to inflammation and oxidation, such as cancer, ischemia-reperfusion injury, and cardiovascular disease. [209, 211, 212] He et al. put forward the concept of "hydrothermotherapy" for the first time, using small palladium nanoparticles as hydrogen carriers and self-catalysts to form stable $\mathrm{PdH}$ 0.2 nanoparticles, realizing tumor delivery by passive targeting and achieving the efficacious PTT and photoacoustic imaging [213]. Palladium hydride nanomaterials (PdH 0.2) are used for targeted hydrogen delivery and controlled release in tumors to achieve efficient hydrogen thermotherapy. However, the hydrogen carrying capacity of the synthesized PdH 0.2 is limited $(\mathrm{H}: \mathrm{Pd}=0.2)$. The synthesis of palladium hydride with a high hydrogen carrying capacity needs to be carried out under high pressure, and the stability of the synthesized product is poor. Recently, to increase the hydrogen loading capacity, a research group proposed using palladium as the coordination center and tetrapyridyl porphyrin as the ligand to synthesize a new type of PdH-MOF nanomaterial in one step. With the help of monatomic palladium in the MOF construction unit, the efficient loading of hydrogen $(\mathrm{H}: \mathrm{Pd}=1)$ and long-term slow release of hydrogen were realized. In addition, hydrogen loaded with monatomic palladium has high catalytic activity as a highly reductive form of hydrogen, which is beneficial for the scavenging of highly oxidizing ROS. The photothermal conversion efficiency of $\mathrm{PdH}-\mathrm{MOF}$ is up to $44.2 \%$, providing a good photoacoustic imaging effect. Combined with the selffluorescence characteristics of porphyrin, it can be used for in vivo tracking and treatment guidance of nanoparticles and can also be combined with photothermal effects to achieve hydrogen-thermal combined antitumor therapy [103].

Although PTT can kill cancer cells at high temperature, this process is often prone to inflammatory reactions, leading to tumor recurrence, metastasis and other adverse consequences [214]. For this reason, Zhang et al. constructed a biofilm camouflage nanodrug (mPDAB) containing PDA and aminoborane (AB). In the acidic tumor microenvironment, $\mathrm{AB}$ releases $\mathrm{H}_{2}$ and reacts with .OH in situ, which reduces the inflammatory response induced by PTT by inhibiting the increase in intracellular ROS induced by PTT and downregulating the levels of TNF- $\alpha$ and IL-6. In addition, after labeling mPDAB with Cy5.5, the biological distribution of nanodrugs in vivo was studied by using a small-animal fluorescence imaging system. The results showed that the fluorescence intensity of Cy5.5 in the tumor site was significantly enhanced over time, indicating that the accumulation of mPDAB in the tumor site was stronger. This is due to biofilm recombination, which gives $\mathrm{mPDAB}$ a longer blood circulation time and enables homologous targeting in vivo. In the mouse tumor model, the distant metastasis of tumors was greatly inhibited in the mPDAB + NIR group because the expression of the tumor proliferation marker Ki67 was significantly decreased (Fig. 7a) [104].

Recently, a Z-type SnS1.68-WO2.41 nanocatalyst was constructed by riveting WO2.41 nanodots on the surface of SnS1.68 nanowires (1.49 eV). WO2.41 nanoparticles injected hot electrons into $\mathrm{SnS1.68}$ nanowires through the surface plasma effect to achieve NIR photocatalytic hydrogen production while enhancing the oxidation ability of the system so that the overexpressed GSH in tumors could be used as a reducer to realize 


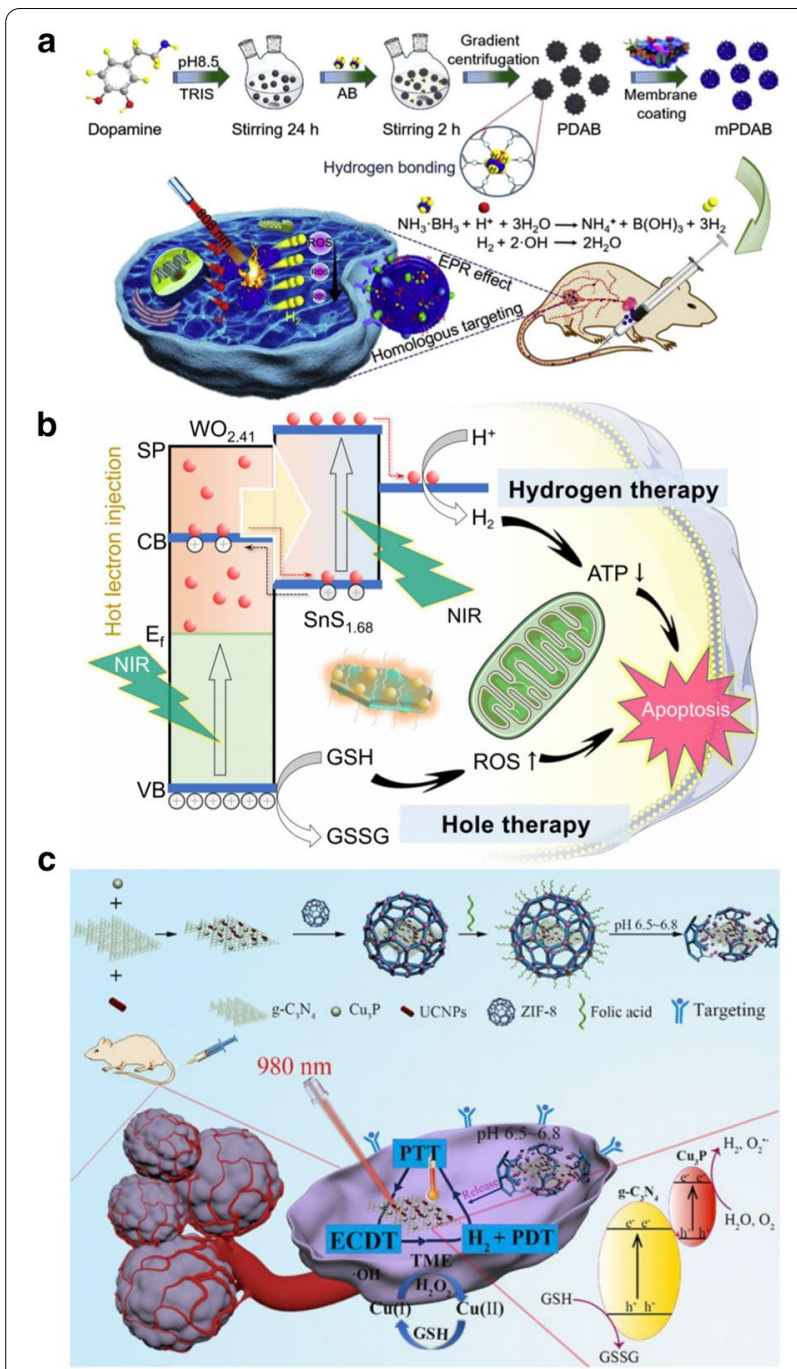

Fig. 7 a Schematic illustration of mPDAB for tumor therapy. Reproduced with permission from Ref [104] Copyright 2019, Elsevier Ltd. $\mathbf{b}$ Schematic illustration of combined hole/hydrogen therapy strategy and mechanisms with the NIR-activable Z-scheme $\mathrm{SnS}_{1.68^{-}}$ $W_{2.41}$ Nanocatalyst. Reproduced with permission from Ref [105]. Copyright 2021, Nature Publishing Group. c Schematic Illustration of the Multimodal Nanoplatform for $\mathrm{H}_{2}$-Mediated Cascade-Amplifying Synergetic Therapy. Reproduced with permission from Ref [106]. Copyright 2020, American Chemical Society

NIR photocatalytic hydrogen production in tumors. The increase in hydrogen and the deprivation of GSH synergistically inhibit the proliferation of cancer cells and induce their apoptosis, leading to the degeneration of overgrown tumor vessels and greatly reducing the content of tumor-associated macrophages (removal of tumor immunosuppression), thus effectively destroying the tumor microenvironment in which cancer cells survive (Fig. 7b) [105].

\section{Photodynamic therapy-triggered $\mathrm{H}_{2}$ prodrug}

$\mathrm{H}_{2}$ can affect the level of ROS in tumor cells through NIR and induce cancer cell injury and apoptosis [215]. However, the low solubility of $\mathrm{H}_{2}$ in water makes it spread easily in the blood and prevents enrichment in the tumor site [209]. It is well known that the water content of the human body ais approximately $70 \%$, which provides us with a way of thinking about how to introduce photocatalytic nanomaterials into tumors and suggests that catalyzing water to produce $\mathrm{H}_{2}$ will be a promising strategy to enhance $\mathrm{H}_{2}$ accumulation in tumors [216]. In recent years, Z-scheme heterojunction systems have been widely used in the generation of PDT and $\mathrm{H}_{2}$ because they can separate electron-hole pairs and improve redox potential [217]. Wang et al. constructed a NIR-photoresponsive in situ hydrolytic hydrogen production nanoplatform (UCCZ-FA) that uses ZIF-8 as its shell and introduces a $\mathrm{gC}_{3} \mathrm{~N}_{4} / \mathrm{Cu}_{3} \mathrm{P}$ Z-scheme heterojunction for light-induced ROS and $\mathrm{H}_{2}$ production. Under the guidance of folic acid, when UCCZ nanoparticles were actively targeted to enrich the tumor, the acidic tumor microenvironment caused the ZIF-8 shell to collapse and release UCC composite nanoparticles. Under $980 \mathrm{~nm}$ laser irradiation, the electrons produced by $\mathrm{gC}_{3} \mathrm{~N}_{4}$ recombine with the electron holes of the Z-scheme, while the high concentration of GSH in the tumor microenvironment can inhibit this process and transfer electrons to Cu3P to catalyze $\mathrm{H}_{2} \mathrm{O}$ to produce $\mathrm{H}_{2}$ and $\mathrm{O}_{2}{ }^{-}$. In addition, $\mathrm{CU}$ (I) reduced $\mathrm{H}_{2} \mathrm{O}_{2}$ to highly toxic $\cdot \mathrm{OH}$ by the Fenton reaction. More importantly, $\mathrm{H}_{2}$ can inhibit the inflammation caused by oxidative stress and PTT in PDT, which promotes the apoptosis of cancer cells by upregulating the expression of Caspase- 3 protein. This combination of GT, PTT, PDT and CDT can effectively inhibit tumor growth (Fig. 7c) [106].

\section{NIR light-triggered $\mathrm{SO}_{\mathbf{2}}$ prodrug}

Sulfur dioxide $\left(\mathrm{SO}_{2}\right)$ has always been considered an air pollutant. In fact, it is also a therapeutic gas transmitter, and can cause oxidative damage to tumor cells by exhausting glutathione in the tumor microenvironment and destroying the membrane structure $[218,219]$. According to recent studies, $\mathrm{SO}_{2}$ has great therapeutic potential in a variety of diseases, including cardiovascular disease, inflammation and cancer [220-223]. However, the biological toxicity and low stability of $\mathrm{SO}_{2}$ gas limit its clinical application in vivo. In this context, it is urgent to develop a gas-producing nanosystem for the targeted transport and controlled release of $\mathrm{SO}_{2}$ gas. To date, small molecular prodrugs based on different endogenous and exogenous stimulus release mechanisms have been developed, including GSH, $\mathrm{pH}$ and light-induced release 
[224-226]. Among them, NIR more easily achieves the on-demand release of $\mathrm{SO}_{2}$ in deep tumor tissues, which can prevent phototoxicity caused by ultraviolet light.

\section{Photothermal therapy-triggered $\mathrm{SO}_{2}$ prodrug}

MDR of cancer cells is one of the main obstacles hindering the effect of cancer chemotherapy [227]. A high concentration of GSH in the tumor microenvironment is one of the important causes of tumor MDR, which protects cancer cells from ROS and maintains tumor redox homeostasis [228]. According to studies, reducing the concentration of GSH can increase the efficacy of anticancer drugs to overcome the MDR of tumor cells [229]. Chen et al. made great progress in the fight against tumor MDR by triggering the release of $\mathrm{SO}_{2}$ gas and DOX by glutathione [224]. However, their research methods cannot control and monitor the release of $\mathrm{SO}_{2}$ and DOX in real time. Therefore, N.D. PradeepSingh et al. designed a $\mathrm{SO}_{2}$ gas drug delivery system (DDS) that overcomes the MDR of tumors by loading the anticancer drug chlorambucil and using GSH and NIR as stimulation conditions. In the tumor microenvironment, DDS reacts with a high concentration of GSH to produce $\mathrm{SO}_{2}$ gas with green fluorescence, which helps to better distinguish cancer cells from normal cells. Under irradiation with NIR light, when the anticancer drug chlorambucil is released at the tumor site, blue fluorescence can be emitted. In addition, the released $\mathrm{SO}_{2}$ can reduce the concentration of GSH and enhance the efficacy of chlorambucil, overcoming the MDR of tumors. This dual stimulus gas delivery system monitors $\mathrm{SO}_{2}$ gas release and chlorambucil in real time under two kinds of fluorescence, which not only enhances the anticancer efficacy but also ensures the biosafety of drugs [107].

\section{Photodynamic therapy-triggered $\mathrm{SO}_{2}$ prodrug}

$\mathrm{SO}_{2}$ can increase the level of ROS, lead to DNA damage, and finally induce apoptosis of cancer cells [230].Yang et al. developed an NIR-photoresponsive $\mathrm{SO}_{2}$ gas nanoplatform (RUCSNs-DM) based on hollow mesoporous silica-embedded UCNPs and $\mathrm{SO}_{2}$ donors (the 1-(2,5-dimethylthien-1,1-dioxide-3-yl)-2-(2,5-dimethylthien-3-yl)-hexaffluorocyclopentene, DM). UCNPs can convert NIR light into ultraviolet light, which leads to the breaking of C-S bonds in DM and the controlled release of $\mathrm{SO}_{2}$. RUCSNs-DM showed good biological safety, and the cytotoxicity to cancer cells without NIR irradiation was negligible. In addition, the $\mathrm{SO}_{2}$ produced by RUCSNs-DM in cancer cells greatly increased the concentration of ROS, resulting in apoptosis and DNA damage. In the mouse tumor model, the antitumor effect of RUCSNs-DM combined with NIR was significantly better than that of the control groups. The 30-day survival rate of mice in this group reached $100 \%$, while showing very low side effects (Fig. 8a) [108].

At present, a large number of precious metal nanoparticles are widely used in antitumor research, among which $\mathrm{Au}-\mathrm{Ag}$ alloys are widely used in photothermal agents because of their excellent photothermal effect [231]. Li et al. constructed a novel $\mathrm{SO}_{2}$ gas generation nanoplatform based on $\mathrm{Au}$ - $\mathrm{Ag}$ high-temperature superconducting nanotubes (Au-Ag HTNS) as carriers and combined it with the $\mathrm{SO}_{2}$ donor benzothiazole sulfinate (BTS). Au-Ag-BTS has excellent heat conversion ability and does not produce thermal attenuation after many experiments, so it can be used as an effective photosensitizer for accurate tumor phototherapy. Under acidic condition, the C-S bond of BTS was destroyed and released $\mathrm{SO} 2$ that combined with PTT up-regulated the expression of Bax and Caspase- 3 and inhibited the expression of Bcl-2, which significantly promoted the apoptosis of cancer cells. According to the fluorescence localization imaging, Au-Ag-BTS HTNS can also be internalized and released $\mathrm{SO} 2$ by lysosome pathway, resulting in the increase of ROS. This method of synergistic elimination of deep tumors by PTT and GT has achieved excellent anti-tumor efficacy. In addition, Au-Ag-BTS HTNS can also be used as a contrast agent for computed tomography $(\mathrm{CT})$ to better guide the antitumor therapy of PTT and PDT. The nanosystem can effectively solve problems related to the biocompatibility, targeting, and intracellular and in vivo targeted delivery of $\mathrm{SO}_{2}$ (Fig. 8b) [109].

In addition, the group constructed gold nanorods@ mesoporous dopamine (GNRS@PDA-BTS) based on BTS. Because of the large amount of amino groups in PDA, the drug loading rate of the nanosystem $\mathrm{SO}_{2}$ is as high as $80 \%$. In an acidic environment, the Cmure $\mathrm{S}$ bond in BTS breaks and releases $\mathrm{SO}_{2}$. PTT can then promote the continuous release of $\mathrm{SO}_{2}$. In addition, $\mathrm{SO}_{2}$ can enhance the efficacy of PDT by increasing the concentration of ROS, upregulating the expression of the proapoptotic proteins p53, bax, and caspase-3, and downregulating the expression of the antiapoptotic protein bcl-2 to effectively promote the apoptosis of cancer cells (Fig. 8c) [110].

\section{Conclusions and outlook}

In summary, gas therapy is a new and promising anticancer therapy strategy. In recent years, the introduction of nanotechnology into the construction of nanogas prodrugs has greatly promoted the development of precision gas nanomedicine in the field of biomedicine. NO, $\mathrm{CO}, \mathrm{H}_{2}, \mathrm{H}_{2} \mathrm{~S}$ and $\mathrm{SO}_{2}$ at appropriate concentrations have excellent antitumor effects with low systemic side effects. NIR light mainly triggers the breaking of chemical bonds in nano-prodrugs by PTT and PDT to release 


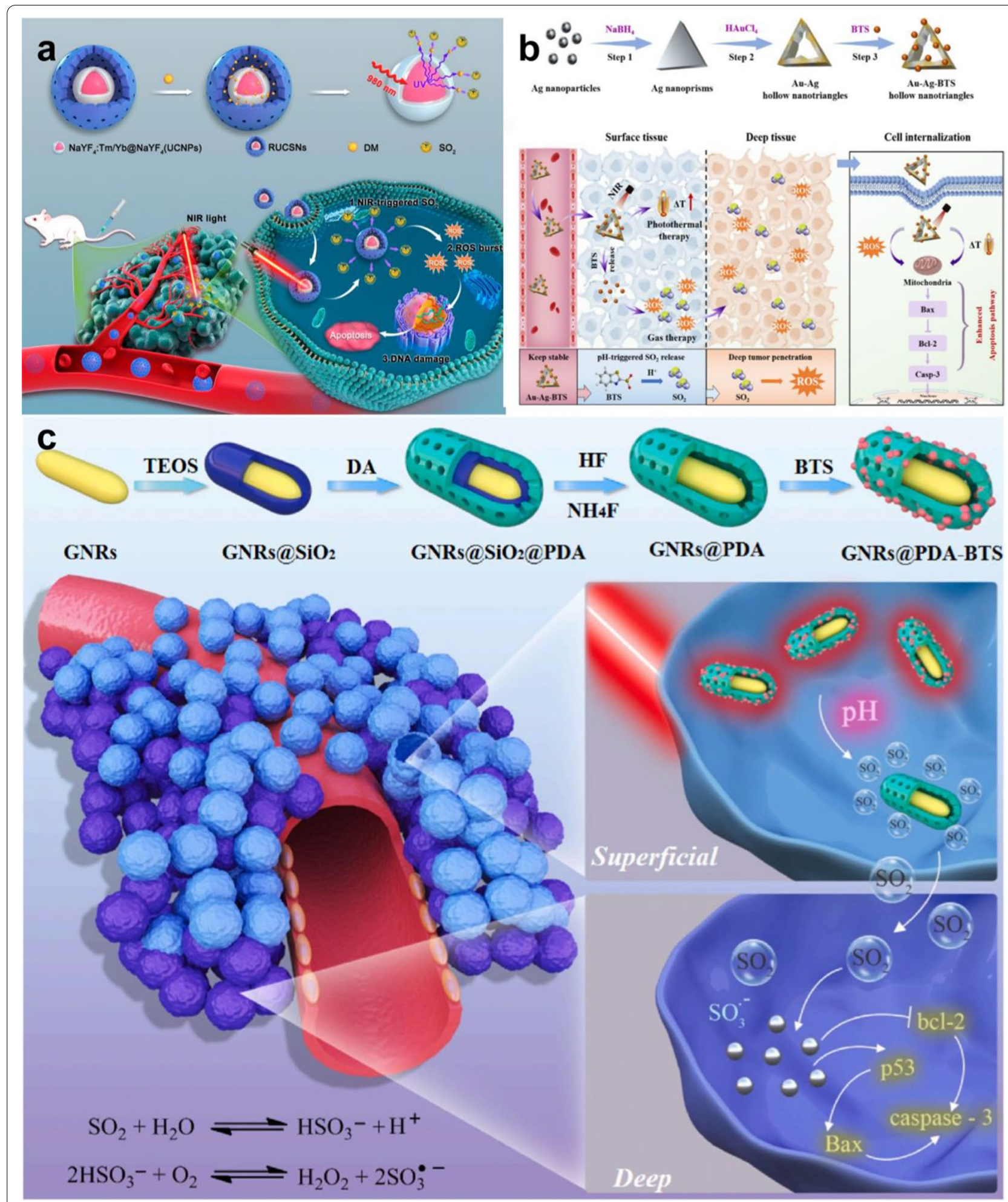

Fig. 8 a Intracellular localized $\mathrm{SO}_{2}$ generation and therapeutic action upon NIR light irradiation after cell uptake of RUCSNs-DM. Reproduced with permission from Ref [108]. Copyright 2019, American Chemical Society. b Schematic illustration of synthetic procedure of Au-Ag-BTS HTNs, and a win-win therapeutic mechanism of Au-Ag-BTS HTNs by acting together on apoptosis protein-Bax and enhanced tumor penetration. Reproduced with permission from Ref [109]. Copyright 2020, Elsevier Ltd. c Schematic illustration of the preparation of GNRs@PDA-BTS and the design of GPBRs for gas therapy and photothermal therapy. Reproduced with permission from Ref [110]. Copyright 2020, Elsevier Ltd 
gas molecules on demand, which is highly controllable. Although great progress has been made in gas therapy, most gas molecules are prone to nonspecific distribution after systemic administration, resulting in strong toxicity to normal tissues. Therefore, developing nanogas prodrugs with targeted transport and controlled release is the main problem before clinical transformation. As a specific noninvasive stimulus with a high penetration depth, NIR light has been widely used in PTT/PDTtriggered gas release from nano-prodrugs. This paper introduces in detail the latest progress in the application of NIR photoresponsive nanogas prodrugs in the field of antitumor therapy in recent years, including how to make use of the unique tumor microenvironment (such as $\mathrm{pH}$, GSH, $\mathrm{H}_{2} \mathrm{O}_{2}$ and ATP) to achieve the precise release of gas molecules in the tumor site. Although gas therapy has achieved exciting results so far, it still faces challenges that urgently need to be solved.

First, although therapeutic gas molecules show good biosafety and low toxicity at appropriate concentrations due to the controlled release of NIR light-responsive nanocarriers, nanocarriers will still have some unpredictable biosafety problems. For example, in some special physiological environments of organisms, nanocarriers show a high degree of instability, which will lead to the premature release of gas molecules. In addition, although inorganic nanomaterials show a high degree of stability, they may pose a threat to the life of organisms as endogenous toxicants. Therefore, the combination of organic-inorganic nanomaterials may be able to overcome the shortcomings of both and while maintaining good biosafety at the same time. However, before the realization of clinical transformation, long-term systematic studies of their biosafety are still needed, including pharmacodynamics, pharmacokinetics and biodegradability. Second, although a variety of NIR light-responsive gas prodrugs have been developed, the progress of gas therapy has been greatly promoted. However, these gas molecules and nanocarriers are rarely used in clinical trials. Some promising nanocarriers have excellent versatility, but the complex preparation process greatly limits the possibility of clinical transformation. In clinical transformation, improving the repeatability, stability and efficiency of nanocarrier preparation is a key step to achieve clinical transformation.

Therefore, as a popular cutting-edge science, gas therapy can not only exert the therapeutic function of gas itself but can also be combined with gas therapy to increase the antitumor effect. Although gas therapy is currently still in its infancy, clinical conversion will benefit patients, which will require the joint efforts and contributions of researchers and experts from various industries.
Acknowledgements

Not applicable.

Authors' contributions

$R L$ and YP write the original draft manuscript; RL, YP and LL prepare the figures; SP, TC and MZ review and edit the manuscript. All authors read and approved the final manuscript.

\section{Funding}

This study is supported by the National Key Research and Development Program of China (Grant No. 2017YFA0205200), the National Natural Science Foundation of China (Grant Nos. 81901857, 21877049, 32171296), Guangdong Provincial Key Laboratory of Tumor Interventional Diagnosis and Treatment (2021B1212040004), Guangdong Natural Science Foundation (2020B1515120043) and Major Program for Tackling Key Problems of Industrial Technology in Guangzhou (201902020013)

Availability of data and materials

Not applicable.

\section{Declarations}

Ethics approval and consent to participate

Not applicable.

Consent for publication

All authors consent to publish.

Competing interests

The authors declared no competing fnancial interest.

Received: 8 September 2021 Accepted: 11 October 2021

Published online: 23 December 2021

\section{References}

1. Siegel RL, Miller KD, Fuchs HE, Jemal A. Cancer statistics, 2021. CA Cancer J Clin. 2021;71(1):7-33.

2. Miller KD, Nogueira L, Mariotto AB, Rowland JH, Yabroff KR, Alfano CM, Jemal A, Kramer JL, Siegel RL. Cancer treatment and survivorship statistics, 2019. CA Cancer J Clin. 2019;69(5):363-85.

3. Siegel RL, Miller KD, Sauer AG, Fedewa SA, Butterly LF, Anderson JC, Cercek A, Smith RA, Jemal A. Colorectal cancer statistics, 2020. CA Cancer J Clin. 2020;70(3):145-64.

4. Brooks RA, Fleming GF, Lastra RR, Lee NK, Moroney JW, Son CH, Tatebe $\mathrm{K}$, Veneris JL. Current recommendations and recent progress in endometrial cancer. CA Cancer J Clin. 2019;69(4):258-79.

5. DeSantis $C E$, Ma J, Sauer AG, Newman LA, Jemal A. Breast cancer statistics, 2017, racial disparity in mortality by state. CA Cancer J Clin. 2017;67(6):439-48.

6. Li R, Xie Y. Nanodrug delivery systems for targeting the endogenous tumor microenvironment and simultaneously overcoming multidrug resistance properties. J Control Release. 2017;251:49-67.

7. Wu M, Li J, Lin X, Wei Z, Zhang D, Zhao B, Liu X, Liu J. Reduction/photo dual-responsive polymeric prodrug nanoparticles for programmed siRNA and doxorubicin delivery. Biomater Sci. 2018;6(6):1457-68.

8. Jin W, Wang Q, Wu M, Li Y, Tang G, Ping Y, Chu PK. Lanthanide-integrated supramolecular polymeric nanoassembly with multiple regulation characteristics for multidrug-resistant cancer therapy. Biomaterials. 2017:129:83-97.

9. Huang H, He L, Zhou W, Qu G, Wang J, Yang N, Gao J, Chen T, Chu PK, Yu X-F. Stable black phosphorus $/ \mathrm{Bi}_{2} \mathrm{O}_{3}$ heterostructures for synergistic cancer radiotherapy. Biomaterials. 2018;171:12-22.

10. Szabo C. Gasotransmitters in cancer: from pathophysiology to experimental therapy. Nat Rev Drug Discov. 2016;15(3):185-203.

11. Szabo C. Hydrogen sulphide and its therapeutic potential. Nat Rev Drug Discov. 2007:6(11):917-35.

12. Fukumura D, Kashiwagi S, Jain RK. The role of nitric oxide in tumour progression. Nat Rev Cancer. 2006;6(7):521-34. 
13. Garcia-Gallego S, Bernardes GJL. Carbon-monoxide-releasing molecules for the delivery of therapeutic CO in vivo. Angew Chem Int Ed. 2014;53(37):9712-21.

14. Ohsawa I, Ishikawa M, Takahashi K, Watanabe M, Nishimaki K, Yamagata K, Katsura Kl, Katayama Y, Asoh S, Ohta S. Hydrogen acts as a therapeutic antioxidant by selectively reducing cytotoxic oxygen radicals. Nat Med. 2007;13(6):688-94.

15. Nicholls M. Nitric oxide discovery Nobel Prize winners Robert F. Furchgott, Louis J. Ignarro, and Ferid Murad shared the Noble Prize in 1998 for their discoveries concerning nitric oxide as a signalling molecule in the cardiovascular system. Eur Heart J. 2019;40(22):1747-9.

16. He L, Cai L-X, Li M-H, Zhang G-L, Zhou L-P, Chen T, Lin M-J, Sun Q-F. Designing a highly stable coordination-driven metallacycle for imaging-guided photodynamic cancer theranostics. Chem Sci. 2020;11(30):7940-9.

17. Lesniak A, Salvati A, Santos-Martinez MJ, Radomski MW, Dawson KA, Aberg C. Nanoparticle adhesion to the cell membrane and its effect on nanoparticle uptake efficiency. J Am Chem Soc. 2013;135(4):1438-44.

18. Zangabad PS, Karimi M, Mehdizadeh F, Malekzad H, Ghasemi A, Bahrami S, Zare H, Moghoofei M, Hekmatmanesh A, Hamblin MR. Nanocaged platforms: modification, drug delivery and nanotoxicity. Opening synthetic cages to release the tiger. Nanoscale. 2017;9(4):1356-92.

19. Karimi M, Avci P, Ahi M, Gazori T, Hamblin MR, Naderi-Manesh H. Evaluation of chitosan-tripolyphosphate nanoparticles as a p-shRNA delivery vector: formulation, optimization and cellular uptake study. J Nanopharm Drug Deliv. 2013;1(3):266-78.

20. Yu L, Hu P, Chen Y. Gas-generating nanoplatforms: material chemistry, multifunctionality, and gas therapy. Adv Mater. 2018. https://doi.org/10. 1002/adma.201801964.

21. Wang $N$, Feng $Y$, Zeng L, Zhao Z, Chen T. Functionalized multiwalled carbon nanotubes as carriers of ruthenium complexes to antagonize cancer multidrug resistance and radioresistance. ACS Appl Mater Interfaces. 2015;7(27):14933-45.

22. Karimi M, Ghasemi A, Zangabad PS, Rahighi R, Basri SMM, Mirshekari H, Amiri M, Pishabad ZS, Aslani A, Bozorgomid M, Ghosh D, Beyzavi A, Vaseghi A, Aref AR, Haghani L, Bahrami S, Hamblin MR. Smart micro/ nanoparticles in stimulus-responsive drug/gene delivery systems. Chem Soc Rev. 2016:45(5):1457-501.

23. Karimi M, Zangabad PS, Ghasemi A, Amiri M, Bahrami M, Malekzad H, Asl HG, Mandieh Z, Bozorgomid M, Ghasemi A, Boyuk MR, Hamblin MR. Temperature-responsive smart nanocarriers for delivery of therapeutic agents: applications and recent advances. ACS Appl Mater Interfaces. 2016;8(33):21107-33.

24. Bordat A, Boissenot T, Nicolas J, Tsapis N. Thermoresponsive polymer nanocarriers for biomedical applications. Adv Drug Delivery Rev. 2019;138:167-92

25. Fleige E, Quadir MA, Haag R. Stimuli-responsive polymeric nanocarriers for the controlled transport of active compounds: concepts and applications. Adv Drug Delivery Rev. 2012;64(9):866-84.

26. Cheng R, Meng F, Deng C, Klok H-A, Zhong Z. Dual and multi-stimuli responsive polymeric nanoparticles for programmed site-specific drug delivery. Biomaterials. 2013;34(14):3647-57.

27. Zhao J, Lee VE, Liu R, Priestley RD. Responsive polymers as smart nanomaterials enable diverse applications. Annu Rev Chem Biomol. 2019;10(1):361-82.

28. Ge Z, Liu S. Functional block copolymer assemblies responsive to tumor and intracellular microenvironments for site-specific drug delivery and enhanced imaging performance. Chem Soc Rev. 2013;42(17):7289-325.

29. Taghizadeh B, Taranejoo S, Monemian SA, Moghaddam ZS, Daliri K, Derakhshankhah H, Derakhshani Z. Classification of stimuli-responsive polymers as anticancer drug delivery systems. Drug Deliv. 2015;22(2):145-55.

30. Liu M, Du H, Zhang W, Zhai G. Internal stimuli-responsive nanocarriers for drug delivery: design strategies and applications. Mat Sci Eng C-Mater. 2017;71:1267-80.

31. Xiao Z, You Y, Liu Y, He L, Zhang D, Cheng Q, Wang D, Chen T, Shi C, Luo L. NIR-triggered blasting nanovesicles for targeted multimodal imageguided synergistic cancer photothermal and chemotherapy. ACS Appl Mater Interfaces. 2021;13(30):35376-88.

32. Li Y, Qian Y, Liu T, Zhang G, Liu S. Light-triggered concomitant enhancement of magnetic resonance imaging contrast performance and drug release rate of functionalized amphiphilic diblock copolymer micelles. Biomacromol. 2012;13(11):3877-86.

33. Lu Y, Xu Y-J, Zhang G-b, Ling D, Wang M-q, Zhou Y, Wu Y-D, Wu T, Hackett MJ, Kim BH, Chang H, Kim J, Hu X-T, Dong L, Lee N, Li F, He J-C, Zhang L, Wen H-Q, Yang B, Choi SH, Hyeon T, Zou D-H. Iron oxide nanoclusters for T-1 magnetic resonance imaging of non-human primates. Nat Biomed Eng. 2017;1 (8):637-43.

34. Huynh E, Leung BYC, Helfield BL, Shakiba M, Gandier J-A, Jin CS, Master ER, Wilson BC, Goertz DE, Zheng G. In situ conversion of porphyrin microbubbles to nanoparticles for multimodality imaging. Nat Nanotechnol. 2015;10(4):325-32.

35. Paproski RJ, Forbrich A, Huynh E, Chen J, Lewis JD, Zheng G, Zemp RJ. Porphyrin nanodroplets: sub-micrometer ultrasound and photoacoustic contrast imaging agents. Small. 2016;12(3):371-80.

36. Moon H, Kang J, Sim C, Kim J, Lee H, Chang JH, Kim H. Multifunctional theranostic contrast agent for photoacoustics- and ultrasound-based tumor diagnosis and ultrasound-stimulated local tumor therapy. J Control Release. 2015:218:63-71.

37. Fang $X$, Li CE, Zheng L, Yang F, Chen T. Dual-targeted selenium nanoparticles for synergistic photothermal therapy and chemotherapy of tumors. Chem Asian J. 2018;13(8):996-1004.

38. Xu C, Pu K. Second near-infrared photothermal materials for combinational nanotheranostics. Chem Soc Rev. 2021;50(2):1111-37.

39. Liu J, Lai H, Xiong Z, Chen B, Chen T. Functionalization and cancertargeting design of ruthenium complexes for precise cancer therapy. Chem Commun. 2019;55(67):9904-14.

40. Liu Z, Chan L, Chen L, Bai Y, Chen T. Facile fabrication of near-infraredresponsive and chitosan-functionalized $\mathrm{Cu}_{2}$ Se nanoparticles for cancer photothermal therapy. Chem Asian J. 2016;11(21):3032-9.

41. Wang J, Chang Y, Luo H, Jiang W, Xu L, Chen T, Zhu X. Designing immunogenic nanotherapeutics for photothermal-triggered immunotherapy involving reprogramming immunosuppression and activating systemic antitumor responses. Biomaterials. 2020. https://doi.org/10.1016/j. biomaterials.2020.120153.

42. Duan L, Liu T, Chen T. Near-infrared laser-triggered drug release in a tellurium nanosystem for simultaneous chemo-photothermal cancer therapy. Biomater Sci. 2021;9(5):1767-78.

43. Liu Z, Chan L, Ye X, Bai Y, Chen T. BSA-based $\mathrm{Cu}_{2}$ Se nanoparticles with multistimuli-responsive drug vehicles for synergistic chemo-photothermal therapy. Colloids Surf B. 2018;172:298-307.

44. Yu S, Huang G, Yuan R, Chen T. A uPAR targeted nanoplatform with an NIR laser-responsive drug release property for tri-modal imaging and synergistic photothermal-chemotherapy of triple-negative breast cancer. Biomater Sci. 2020;8(2):720-38.

45. Fu JJ, Chen MY, Li JX, Zhou JH, Xie SN, Yuan P, Tang B, Liu CC. Retraction note to: injectable hydrogel encapsulating Cu2MnS2 nanoplates for photothermal therapy against breast cancer. J Nanobiotechnol. 2021;19(1):35.

46. Xu P, Wang R, Yang W, Liu Y, He D, Ye Z, Chen D, Ding Y, Tu J, Shen Y. Correction to: A DM1-doped porous gold nanoshell system for NIR accelerated redox-responsive release and triple modal imaging guided photothermal synergistic chemotherapy. J Nanobiotechnol. 2021:19(1):119

47. Zhao B, Wang H, Dong W, Cheng S, Li H, Tan J, Zhou J, He W, Li L, Zhang J, Luo G, Qian W. Correction to: a multifunctional platform with single-NIR-laser-triggered photothermal and NO release for synergistic therapy against multidrug-resistant Gram-negative bacteria and their biofilms. J Nanobiotechnol. 2020;18(1):137

48. Sheth RA, Wen X, Li J, Melancon MP, Ji X, Andrew Wang Y, Hsiao C-H, Chow DSL, Whitley EM, Li C, Gupta S. Doxorubicin-loaded hollow gold nanospheres for dual photothermal ablation and chemoembolization therapy. Cancer Nanotechnol. 2020;11(1):6.

49. Pakravan A, Azizi M, Rahimi F, Bani F, Mahmoudzadeh F, Salehi R, Mahkam M. Comparative effect of thermo/pH-responsive polymercoated gold nanocages and hollow nanostars on chemo-photothermal therapy of breast cancer cells. Cancer Nanotechnol. 2021;12(1):19.

50. Khan NU, Lin J, Younas MR, Liu X, Shen L. Synthesis of gold nanorods and their performance in the field of cancer cell imaging and photothermal therapy. Cancer Nanotechnol. 2021;12(1):20.

51. Marangon I, Menard-Moyon C, Silva AKA, Bianco A, Luciani N, Gazeau F. Synergic mechanisms of photothermal and photodynamic therapies 
mediated by photosensitizer/carbon nanotube complexes. Carbon. 2016;97:110-23.

52. Liu S, Pan X, Liu H. Two-dimensional nanomaterials for photothermal therapy. Angew Chem Int Ed. 2020;59(15):5890-900.

53. Jung HS, Verwilst P, Sharma A, Shin J, Sessler JL, Kim JS. Organic molecule-based photothermal agents: an expanding photothermal therapy universe. Chem Soc Rev. 2018:47(7):2280-97.

54. Tan A, Madani SY, Rajadas J, Pastorin G, Seifalian AM. Synergistic photothermal ablative effects of functionalizing carbon nanotubes with a POSS-PCU nanocomposite polymer. J Nanobiotechnol. 2012;10(1):34.

55. Sun Y, Zhai W, Liu X, Song X, Gao X, Xu K, Tang B. Homotypic cell membrane-cloaked biomimetic nanocarrier for the accurate photothermalchemotherapy treatment of recurrent hepatocellular carcinoma. J Nanobiotechnol. 2020;18(1):60.

56. Xu Z, Zhang Y, Zhou W, Wang L, Xu G, Ma M, Liu F, Wang Z, Wang Y, Kong T, Zhao B, Wu W, Yang C. NIR-II-activated biocompatible hollow nanocarbons for cancer photothermal therapy. J Nanobiotechnol. 2021;19(1):137.

57. Jiang Q, Liu L, Li Q, Cao Y, Chen D, Du Q, Yang X, Huang D, Pei R, Chen $X$, Huang G. NIR-laser-triggered gadolinium-doped carbon dots for magnetic resonance imaging, drug delivery and combined photothermal chemotherapy for triple negative breast cancer. J Nanobiotechnol. 2021;19(1):64

58. Chilakamarthi U, Giribabu L. Photodynamic therapy: past, present and future. Chem Rec. 2017;17(8):775-802.

59. Li X, Kwon N, Guo T, Liu Z, Yoon J. Innovative strategies for hypoxic-tumor photodynamic therapy. Angew Chem Int Ed. 2018;57(36):11522-31.

60. Donohoe C, Senge MO, Arnaut LG, Gomes-da-Silva LC. Cell death in photodynamic therapy: from oxidative stress to anti-tumor immunity. Biochim Biophys Acta Rev Cancer. 2019. https://doi.org/10.1016/j. bbcan.2019.07.003.

61. MacKay S, Jerjes W, Upile T, Abbas S, Hamdoon Z, Nhembe F, Patel S, Shah P, Vourvachis M, Morley S, Hopper C. Ultrasound guided interstitial photodynamic therapy of deep seated lesions. Head Neck Oncol. 2009;1 (1):P10.

62. Nhembe F, Jerjes W, Upile T, Abbas S, Vaz F, Hopper C. Subglottic carcinoma effectively treated with surgery and adjuvant photodynamic therapy. Head Neck Oncol. 2009; 1 (1):P12.

63. Jerjes W, Upile T, Hamdoon Z, Nhembe F, Bhandari R, Mackay S, Mosse CA, Morley S, Hopper C. Photodynamic therapy as the "last hope" for tonque-based carcinoma. Head Neck Oncol. 2010;2(1):O27.

64. Han J, Hwang HS, Na K. TRAll-secreting human mesenchymal stem cells engineered by a non-viral vector and photochemical internalization for pancreatic cancer gene therapy. Biomaterials. 2018;182:259-68.

65. Norum O-J, Fremstedal ASV, Weyergang A, Golab J, Berg K. Photochemical delivery of bleomycin induces T-cell activation of importance for curative effect and systemic anti-tumor immunity. J Control Release. 2017:268:120-7.

66. Xu X, Li Y, Liang Q, Song Z, Li F, He H, Wang J, Zhu L, Lin Z, Yin L. Efficient gene delivery mediated by a helical polypeptide: controlling the membrane activity via multivalency and light-assisted photochemical internalization (PCI). ACS Appl Mater Interfaces. 2018;10(1):256-66.

67. Schineis P, Kotkowska ZK, Vogel-Kindgen S, Friess MC, Theisen M, Schwyter D, Hausammann L, Subedi S, Varypataki EM, Waeckerle-Men Y, Kolm I, Kuendig TM, Hogset A, Gander B, Halin C, Johansen P. Photochemical internalization (PCI)-mediated activation of CD8 T cells involves antigen uptake and CCR7-mediated transport by migratory dendritic cells to draining lymph nodes. J Control Release. 2021;332:96-108.

68. Maeda H, Wu J, Sawa T, Matsumura Y, Hori K. Tumor vascular permeability and the EPR effect in macromolecular therapeutics: a review. J Control Release. 2000;65(1-2):271-84.

69. Jain RK, Stylianopoulos T. Delivering nanomedicine to solid tumors. Nat Rev Clin Oncol. 2010;7(11):653-64.

70. Chen P, Chen X, Hepfer RG, Damon BJ, Shi C, Yao JJ, Coombs MC, Kern $\mathrm{MJ}$, Ye T, Yao H. A noninvasive fluorescence imaging-based platform measures 3D anisotropic extracellular diffusion. Nat Commun. 2021. https://doi.org/10.1038/s41467-021-22221-0.

71. Wu Y, Yuan $\mathrm{M}$, Song J, Chen $\mathrm{X}$, Yang $\mathrm{H}$. Hydrogen gas from inflammation treatment to cancer therapy. ACS Nano. 2019;13(8):8505-11.
72. Lin H, Chen Y, Shi J. Nanoparticle-triggered in situ catalytic chemical reactions for tumour-specific therapy. Chem Soc Rev. 2018;47(6):1938-58

73. Zhang X, Tian G, Yin W, Wang L, Zheng X, Yan L, Li J, Su H, Chen C, Gu Z, Zhao Y. Controllable generation of nitric oxide by near-infrared-sensitized upconversion nanoparticles for tumor therapy. Adv Funct Mater. 2015;25(20):3049-56.

74. Fan J, He N, He Q, Liu Y, Ma Y, Fu X, Liu Y, Huang P, Chen X. A novel selfassembled sandwich nanomedicine for NIR-responsive release of NO. Nanoscale. 2015;7(47):20055-62.

75. Chen L, He Q, Lei M, Xiong L, Shi K, Tan L, Jin Z, Wang T, Qian Z. Facile coordination-precipitation route to insoluble metal roussin's black salts for NIR-responsive release of no for anti-metastasis. ACS Appl Mater Interfaces. 2017;9(50):44258-44258.

76. Yin $H$, Guan $X$, Lin H, Pu Y, Fang Y, Yue W, Zhou B, Wang Q, Chen Y, Xu H. Nanomedicine-enabled photonic thermogaseous cancer therapy. Adv Sci. 2020. https://doi.org/10.1002/advs.201901954.

77. Zhang X, Du J, Guo Z, Yu J, Gao Q, Yin W, Zhu S, Gu Z, Zhao Y. Efficient near infrared light triggered nitric oxide release nanocomposites for sensitizing mild photothermal therapy. Adv Sci. 2019. https://doi.org/ 10.1002/advs.201801122.

78. Yu Y-T, Shi S-W, Wang Y, Zhang Q-L, Gao S-H, Yang S-P, Liu J-G. A ruthenium nitrosyl-functionalized magnetic nanoplatform with nearinfrared light-controlled nitric oxide delivery and photothermal effect for enhanced antitumor and antibacterial therapy. ACS Appl Mater Interfaces. 2020;12(1):312-21.

79. Guo R, Tian Y, Wang Y, Yang W. Near-infrared laser-triggered nitric oxide nanogenerators for the reversal of multidrug resistance in cancer. Adv Funct Mater. 2017. https://doi.org/10.1002/adfm.201606398.

80. Ding Y, Du C, Qian J, Dong C-M. NIR-responsive polypeptide nanocomposite generates no gas, mild photothermia, and chemotherapy to reverse multidrug-resistant cancer. Nano Lett. 2019;19(7):4362-70.

81. Feng T, Wan J, Li P, Ran H, Chen H, Wang Z, Zhang L. A novel NIR-controlled NO release of sodium nitroprusside-doped Prussian blue nanoparticle for synergistic tumor treatment. Biomaterials. 2019. https://doi, org/10.1016/j.biomaterials.2019.05.024.

82. Li J, Jiang R, Wang Q, Li X, Hu X, Yuan Y, Lu X, Wang W, Huang W, Fan Q. Semiconducting polymer nanotheranostics for NIR-II/Photoacoustic imaging-guided photothermal initiated nitric oxide/photothermal therapy. Biomaterials. 2019. https://doi.org/10.1016/j.biomaterials.2019. 119304.

83. Xiang H-J, Deng Q, An L, Guo M, Yang S-P, Liu J-G. Tumor cell specific and lysosome-targeted delivery of nitric oxide for enhanced photodynamic therapy triggered by $808 \mathrm{~nm}$ near-infrared light. Chem Commun. 2016;52(1):148-51.

84. Wan S-S, Zeng J-Y, Cheng H, Zhang X-Z. ROS-induced NO generation for gas therapy and sensitizing photodynamic therapy of tumor. Biomaterials. 2018;185:51-62.

85. Wang Y, Huang X, Tang Y, Zou J, Wang P, Zhang Y, Si W, Huang W, Dong $X$. A light-induced nitric oxide controllable release nano-platform based on diketopyrrolopyrrole derivatives for $\mathrm{pH}$-responsive photodynamic/ photothermal synergistic cancer therapy. Chem Sci. 2018;9(42):8103-9.

86. Wang $L$, Chang Y, Feng Y, Li X, Cheng Y, Jian H, Ma X, Zheng R, Wu X, Xu K, Zhang H. Nitric oxide stimulated programmable drug release of nanosystem for multidrug resistance cancer therapy. Nano Lett. 2019;19(10):6800-11.

87. Li W-P, Su C-H, Tsao L-C, Chang C-T, Hsu Y-P, Yeh C-S. Controllable CO release following near infrared light-induced cleavage of iron carbonyl derivatized Prussian blue nanoparticles for CO-assisted synergistic treatment. ACS Nano. 2016;10(12):11027-36.

88. Wang C, LiY, Shi X, Zhou J, Zhou L, Wei S. Use of an NIR-light-responsive CO nanodonor to improve the EPR effect in photothermal cancer treatment. Chem Commun. 2018;54(95):13403-6.

89. Tang W, Fan W, Wang Z, Zhang W, Zhou S, Liu Y, Yang Z, Shao E, Zhang G, Jacobson O, Shan L, Tian R, Cheng S, Lin L, Dai Y, Shen Z, Niu G, Xie J, Chen X. Acidity/reducibility dual-responsive hollow mesoporous organosilica nanoplatforms for tumor-specific self-assembly and synergistic therapy. ACS Nano. 2018;12(12):12269-83.

90. Yao X, Yang P, Jin Z, Jiang Q, Guo R, Xie R, He Q, Yang W. Multifunctional nanoplatform for photoacoustic imaging-guided combined therapy enhanced by CO induced ferroptosis. Biomaterials. 2019;197:268-83. 
91. Yao J, Liu Y, Wang J, Jiang Q, She D, Guo H, Sun N, Pang Z, Deng C, Yang $W$, Shen S. On-demand CO release for amplification of chemotherapy by MOF functionalized magnetic carbon nanoparticles with NIR irradiation. Biomaterials. 2019;195:51-62.

92. Wang S-B, Zhang C, Ye J-J, Zou M-Z, Liu C-J, Zhang X-Z. Near-infrared light responsive nanoreactor for simultaneous tumor photothermal therapy and carbon monoxide-mediated anti-inflammation. ACS Cent Sci. 2020;6(4):555-65.

93. Wu L, Cai X, Zhu H, Li J, Shi D, Su D, Yue D, Gu Z. PDT-driven highly efficient intracellular delivery and controlled release of co in combination with sufficient singlet oxygen production for synergistic anticancer therapy. Adv Funct Mater. 2018. https://doi.org/10.1002/adfm.20180 4324.

94. Guan Q, Zhou L-L, Li Y-A, Dong Y-B. A nanoscale metal-organic framework for combined photodynamic and starvation therapy in treating breast tumors. Chem Commun. 2019;55(99):14898-901.

95. LiY, Dang J, Liang Q, Yin L. Carbon monoxide (CO)-strengthened cooperative bioreductive anti-tumor therapy via mitochondrial exhaustion and hypoxia induction. Biomaterials. 2019;209:138-51.

96. Li Y, Dang J, Liang Q, Yin L. Thermal-responsive carbon monoxide (CO) delivery expedites metabolic exhaustion of cancer cells toward reversal of chemotherapy resistance. ACS Cent Sci. 2019;5(6):1044-58.

97. Sun P, Jia L, Hai J, Lu S, Chen F, Liang K, Sun S, Liu H, Fu X, Zhu Y, Wang B. Tumor microenvironment-"AND" near-infrared light-activated coordination polymer nanoprodrug for On-Demand CO-Sensitized synergistic cancer therapy. Adv Healthc Mater. 2021. https://doi.org/10.1002/ adhm.202001728.

98. Wang X-S, Zeng J-Y, Li M-J, Li Q-R, Gao F, Zhang X-Z. Highly stable iron carbonyl complex delivery nanosystem for improving cancer therapy. ACS Nano. 2020;14(8):9848-60.

99. Chen W, Chen M, Zang Q, Wang L, Tang F, Han Y, Yang C, Deng L, Liu Y-N. NIR light controlled release of caged hydrogen sulfide based on upconversion nanoparticles. Chem Commun. 2015;51(44):9193-6.

100. Li H, Yao Y, Shi H, Lei Y, Huang Y, Wang K, He X, Liu J. A near-infrared light-responsive nanocomposite for photothermal release of $\mathrm{H}_{2} \mathrm{~S}$ and suppression of cell viability. J Mater Chem B. 2019;7(39):5992-7.

101. Zheng Z, Chen Q, Dai R, Jia Z, Yang C, Peng X, Zhang R. A continuous stimuli-responsive system for NIR-II fluorescence/photoacoustic imaging guided photothermal/gas synergistic therapy. Nanoscale. 2020;12(21):11562-72.

102. Fang C, Cen D, Wang Y, Wu Y, Cai X, Xiang L, Han G. ZnS@ZIF-8 core-shell nanoparticles incorporated with ICG and TPZ to enable $\mathrm{H}_{2} \mathrm{~S}$-amplified synergistic therapy. Theranostics. 2020;10(17):7671-82.

103. Zhou G, Wang YS, Jin Z, Zhao P, Zhang H, Wen Y, He Q. Porphyrin-palladium hydride MOF nanoparticles for tumor-targeting photoacoustic imaging-guided hydrogenothermal cancer therapy. Nanoscale Horiz. 2019:4(5):1185-93.

104. Zhang C, Zheng D-W, Li C-X, Zou M-Z, Yu W-Y, Liu M-D, Peng S-Y, Zhong $Z-L$, Zhang $X-Z$. Hydrogen gas improves photothermal therapy of tumor and restrains the relapse of distant dormant tumor. Biomaterials. 2019. https://doi.org/10.1016/j.biomaterials.2019.119472.

105. Zhao B, Wang Y, Yao X, Chen D, Fan M, Jin Z, He Q. Photocatalysismediated drug-free sustainable cancer therapy using nanocatalyst. Nat Commun. 2021. https://doi.org/10.1038/s41467-021-21618-1.

106. Wang $\mathrm{Q}$, Ji Y, Shi J, Wang L. NIR-driven water splitting $\mathrm{H}_{2}$ production nanoplatform for $\mathrm{H}_{2}$-mediated cascade-amplifying synergetic cancer therapy. ACS Appl Mater Interfaces. 2020;12(21):23677-88.

107. Roy B, Kundu M, Singh AK, Singha T, Bhattacharya S, Datta PK, Mandal $M$, Singh NDP. Stepwise dual stimuli triggered dual drug release by a single naphthalene based two-photon chromophore to reverse MDR for alkylating agents with dual surveillance in uncaging steps. Chem Commun. 2019;55(87):13140-3.

108. Li S, Liu R, Jiang X, Qu Y, Song X, Huang G, Fu N, Lin L, Song J, Chen $X$, Yang $H$. Near-infrared light-triggered sulfur dioxide gas therapy of cancer. ACS Nano. 2019;13(2):2103-13.

109. Xu M, Lu Q, Song Y, Yang L, Li J, Li N. Enhanced Bax upregulating in mitochondria for deep tumor therapy based on $\mathrm{SO}_{2}$ prodrug loaded Au-Ag hollow nanotriangle. Biomaterials. 2020. https://doi.org/10. 1016/j.biomaterials.2020.120076

110. Lu Q, LuT, Xu M, Yang L, Song Y, Li N. SO 2 prodrug doped nanorattles with extra-high drug payload for "collusion inside and outside"
photothermal/pH triggered - gas therapy. Biomaterials. 2020. https:// doi.org/10.1016/j.biomaterials.2020.120236.

111. Wang Z, Feng C, Zhao H, Ren X, Peng S, Zuo Z. Autoregulation of inducible nitric oxide synthase expression by RNA interference provides neuroprotection in neonatal rats. Theranostics. 2015;5(5):504-14.

112. Lin J-J, Lin Y, Zhao T-Z, Zhang C-K, Zhang T, Chen X-L, Ding J-Q, Chang T, Zhang Z, Sun C, Zhao D-D, Zhu J-L, Li Z-Y, Li J-L. Melatonin suppresses neuropathic pain via $\mathrm{MT}_{2}$-dependent and -independent pathways in dorsal root ganglia neurons of mice. Theranostics. 2017;7(7):2015-32.

113. Cureton N, Korotkova I, Baker B, Greenwood S, Wareing M, Kotamraju VR, Teesalu T, Cellesi F, Tirelli N, Ruoslahti E, Aplin JD, Harris LK. Selective targeting of a novel vasodilator to the uterine vasculature to treat impaired uteroplacental perfusion in pregnancy. Theranostics. 2017;7(15):3715-31.

114. Zhou H-f, Yan H, Hu Y, Springer LE, Yang X, Wickline SA, Pan D, Lanza GM, Pham CTN. Fumagillin prodrug nanotherapy suppresses macrophage inflammatory response via endothelial nitric oxide. ACS Nano. 2014;8(7):7305-17.

115. Chandrawati R, Chang JYH, Reina-Torres E, Jumeaux C, Sherwood JM, Stamer WD, Zelikin AN, Overby DR, Stevens MM. Localized and controlled delivery of nitric oxide to the conventional outflow pathway via enzyme biocatalysis: toward therapy for glaucoma. Adv Mater. 2017. https://doi.org/10.1002/adma.201604932.

116. Bogdan C. Nitric oxide and the immune response. Nat Immunol. 2001;2(10):907-16.

117. Dong X, Liu H-J, Feng H-Y, Yang S-C, Liu X-L, Lai X, Lu Q, Lovell JF, Chen $\mathrm{H}-\mathrm{Z}$, Fang $\mathrm{C}$. Enhanced drug delivery by nanoscale integration of a nitric oxide donor to induce tumor collagen depletion. Nano Lett. 2019;19(2):997-1008

118. Chen X, Jia F, Li Y, Deng Y, Huang Y, Liu W, Jin Q, Ji J. Nitric oxide-induced stromal depletion for improved nanoparticle penetration in pancreatic cancer treatment. Biomaterials. 2020. https://doi.org/10.1016/j.bioma terials.2020.119999.

119. Qian Y, Matson JB. Gasotransmitter delivery via self-assembling peptides: treating diseases with natural signaling gases. Adv Drug Delivery Rev. 2017;110:137-56.

120. Ridnour LA, Thomas DD, Donzelli S, Espey MG, Roberts DD, Wink DA, Isenberg JS. The biphasic nature of nitric oxide responses in tumor biology. Antioxid Redox Signal. 2006;8(7-8):1329-37.

121. Jin Z, Wen Y, Hu Y, Chen W, Zheng X, Guo W, Wang T, Qian Z, Su B-L, He Q. MRI-guided and ultrasound-triggered release of NO by advanced nanomedicine. Nanoscale. 2017;9(10):3637-45.

122. Kim J, Yung BC, Kim WJ, Chen X. Combination of nitric oxide and drug delivery systems: tools for overcoming drug resistance in chemotherapy. J Control Release. 2017;263:223-30.

123. Yuan Z, Lin C, He Y, Tao B, Chen M, Zhang J, Liu P, Cai K. Near-infrared light-triggered nitric-oxide-enhanced photodynamic therapy and lowtemperature photothermal therapy for biofilm elimination. ACS Nano. 2020;14(3):3546-62.

124. Hu X, Mandika C, He L, You Y, Chang Y, Wang J, Chen T, Zhu X. Construction of urokinase-type plasminogen activator receptor-targeted heterostructures for efficient photothermal chemotherapy against cervical cancer to achieve simultaneous anticancer and antiangiogenesis. ACS Appl Mater Interfaces. 2019;11(43):39688-705.

125. Huerta S, Chilka S, Bonavida B. Nitric oxide donors: novel cancer therapeutics (review). Int J Oncol. 2008;33(5):909-27.

126. Lee HJ, Kim DE, Park DJ, Choi GH, Yang D-N, Heo JS, Lee SC. pH-Responsive mineralized nanoparticles as stable nanocarriers for intracellular nitric oxide delivery. Colloids Surf B. 2016;146:1-8.

127. Zhang X, Guo Z, Liu J, Tian G, Chen K, Yu S, Gu Z. Near infrared light triggered nitric oxide releasing platform based on upconversion nanoparticles for synergistic therapy of cancer stem-like cells. Sci Bull. 2017;62(14):985-96.

128. Fry NL, Mascharak PK. Photoactive ruthenium nitrosyls as NO donors: how to sensitize them toward visible light. Acc Chem Res. 2011;44(4):289-98.

129. Rose MJ, Mascharak PK. Photoactive ruthenium nitrosyls: effects of light and potential application as NO donors. Coord Chem Rev 2008:252(18-20):2093-114. 
130. Shi J, Kantoff PW, Wooster R, Farokhzad OC. Cancer nanomedicine: progress, challenges and opportunities. Nat Rev Cancer. 2017;17(1):20-37.

131. Robey RW, Pluchino KM, Hall MD, Fojo AT, Bates SE, Gottesman MM. Revisiting the role of $A B C$ transporters in multidrug-resistant cancer. Nat Rev Cancer. 2018;18(7):452-64.

132. Nishiyama N, Matsumura Y, Kataoka K. Development of polymeric micelles for targeting intractable cancers. Cancer Sci. 2016;107(7):867-74

133. Chung M-F, Liu H-Y, Lin K-J, Chia W-T, Sung H-W. A pH-responsive carrier system that generates NO bubbles to trigger drug release and reverse P-glycoprotein-mediated multidrug resistance. Angew Chem Int Ed. 2015:54(34):9890-3.

134. Deng X, Liu H, Xu Y, Chan L, Xie J, Xiong Z, Tang Z, Yang F, Chen T. Designing highly stable ferrous selenide-black phosphorus nanosheets heteronanostructure via P-Se bond for MRI-guided photothermal therapy. J Nanobiotechnol. 2021. https://doi.org/10.1186/ s12951-021-00905-5.

135. Gehring J, Trepka B, Klinkenberg N, Bronner H, Schleheck D, Polarz S. Sunlight-triggered nanoparticle synergy: teamwork of reactive oxygen species and nitric oxide released from mesoporous organosilica with advanced antibacterial activity. J Am Chem Soc. 2016;138(9):3076-84.

136. Fehrenbacher N, Jaattela M. Lysosornes as targets for cancer therapy. Cancer Res. 2005;65(8):2993-5.

137. Sun T, Zhang YS, Pang B, Hyun DC, Yang M, Xia Y. Engineered nanoparticles for drug delivery in cancer therapy. Angew Chem Int Ed. 2014;53(46):12320-64.

138. Cai Y, Liang P, Tang Q, Si W, Chen P, Zhang Q, Dong X. Diketopyrrolopyrrole-based photosensitizers conjugated with chemotherapeutic agents for multimodal tumor therapy. ACS Appl Mater Interfaces. 2017;9(36):30398-405

139. Cai Y, Liang P, Tang Q, Yang X, Si W, Huang W, Zhang Q, Dong X. Diketopyrrolopyrrole-triphenylamine organic nanoparticles as multifunctional reagents for photoacoustic imaging-guided photodynamic/photothermal synergistic tumor therapy. ACS Nano. 2017;11(1):1054-63.

140. Shi H, Sun W, Wang Q, Gu G, Si W, Huang W, Zhang Q, Dong X. A thienylsubstituted diketopyrrolopyrrole derivative with efficient reactive oxygen species generation for photodynamic therapy. ChemPlusChem. 2016:81(6):515-20.

141. Motterlini R, Otterbein LE. The therapeutic potential of carbon monoxide. Nat Rev Drug Discov. 2010;9(9):728-43.

142. Dulak J, Deshane J, Jozkowicz A, Agarwal A. Heme oxygenase-1 and carbon monoxide in vascular pathobiology. Circulation. 2008;117(2):231-41.

143. Wu LY, Wang R. Carbon monoxide: endogenous production, physiological functions, and pharmacological applications. Pharmacol Rev. 2005:57(4):585-630

144. Foresti R, Bani-Hani MG, Motterlini R. Use of carbon monoxide as a therapeutic agent: promises and challenges. Intensive Care Med. 2008:34(4):649-58.

145. Otterbein LE, Zuckerbraun BS, Haga M, Liu F, Song RP, Usheva A, Stachulak C, Bodyak N, Smith RN, Csizmadia E, Tyagi S, Akamatsu Y, Flavell RJ, Billiar TR, Tzeng E, Bach FH, Choi AMK, Soares MP. Carbon monoxide suppresses arteriosclerotic lesions associated with chronic graft rejection and with balloon injury. Nat Med. 2003;9(2):183-90.

146. Nassour I, Kautza B, Rubin M, Escobar D, Luciano J, Loughran P Gomez H, Scott J, Gallo D, Brumfield J, Otterbein LE, Zuckerbraun BS. Carbon monoxide protects against hemorrhagic shock and resuscitation-induced microcirculatory injury and tissue injury. Shock. 2015:43(2):166-71.

147. Wegiel B, Gallo D, Csizmadia E, Harris C, Belcher J, Vercellotti GM, Penacho N, Seth P, Sukhatme V, Ahmed A, Pandolfi PP, Helczynski L, Bjartell A, Persson JL, Otterbein LE. Carbon monoxide expedites metabolic exhaustion to inhibit tumor growth. Cancer Res. 2013;73(23):7009-21.

148. Yin H, Fang J, Liao L, Maeda H, Su Q. Upregulation of heme oxygenase-1 in colorectal cancer patients with increased circulation carbon monoxide levels, potentially affects chemotherapeutic sensitivity. BMC Cancer. 2014. https://doi.org/10.1186/1471-2407-14-436.

149. Shokouhimehr M, Soehnlen ES, Hao J, Griswold M, Flask C, Fan X, Basilion JP, Basu S, Huang SD. Dual purpose Prussian blue nanoparticles for cellular imaging and drug delivery: a new generation of T-1-weighted
MRI contrast and small molecule delivery agents. J Mater Chem. 2010;20(25):5251-9.

150. Shi S, Huang Y, Chen X, Weng J, Zheng N. Optimization of surface coating on small Pd nanosheets for in vivo near-infrared photothermal therapy of tumor (vol 7, pg 14369, 2015). ACS Appl Mater Interfaces. 2016;8(45):31482-31482.

151. LiY, Shi J. Hollow-structured mesoporous materials: chemical synthesis, functionalization and applications. Adv Mater. 2014;26(20):3176-205.

152. Fang Y, Lv Y, Gong F, Wu Z, Li X, Zhu H, Zhou L, Yao C, Zhang F, Zheng G, Zhao D. Interface tension-induced synthesis of monodispersed mesoporous carbon hemispheres. J Am Chem Soc. 2015;137(8):2808-11.

153. Wu M-X, Yang Y-W. Metal-organic framework (MOF)-based drug/cargo delivery and cancer therapy. Adv Mater. 2017. https://doi.org/10.1002/ adma.201606134.

154. Intlekofer AM, Finley LWS. Metabolic signatures of cancer cells and stem cells. Nat Metab. 2019;1(2):177-88.

155. Agostinis P, Berg K, Cengel KA, Foster TH, Girotti AW, Gollnick SO, Hahn SM, Hamblin MR, Juzeniene A, Kessel D, Korbelik M, Moan J, Mroz P, Nowis D, Piette J, Wilson BC, Golab J. Photodynamic therapy of cancer: an update. CA Cancer J Clin. 2011;61(4):250-81.

156. Song G, Chen Y, Liang C, Yi X, Liu J, Sun X, Shen S, Yang K, Liu Z. Catalase-loaded TaOx nanoshells as bio-nanoreactors combining high-z element and enzyme delivery for enhancing radiotherapy. Adv Mater. 2016:28(33):7143.

157. Carvalho TMA, Cardoso HJ, Figueira MI, Vaz CV, Socorro S. The peculiarities of cancer cell metabolism: a route to metastasization and a target for therapy. Eur J Med Chem. 2019;171:343-63.

158. Liu Z, Li T, Han F, Wang Y, Gan Y, Shi J, Wang T, Akhtar ML, Li Y. A cascadereaction enabled synergistic cancer starvation/ROS-mediated/chemotherapy with an enzyme modified Fe-based MOF. Biomaterials Sci. 2019;7(9):3683-92.

159. Liu Y, Liu Y, Bu W, Cheng C, Zuo C, Xiao Q, Sun Y, Ni D, Zhang C, Liu J, Shi J. Hypoxia induced by upconversion-based photodynamic therapy: towards highly effective synergistic bioreductive therapy in tumors. Angew Chem Int Ed. 2015;54(28):8105-9.

160. HuY, LvT, Ma Y, Xu J, Zhang Y, Hou Y, Huang Z, Ding Y. Nanoscale coordination polymers for synergistic no and chemodynamic therapy of liver cancer (vol 19, pg 2731, 2019). Nano Lett. 2019;19(11):8342-8342.

161. Li M, Wang C, Di Z, Li H, Zhang J, Xue W, Zhao M, Zhang K, Zhao Y, Li L. Engineering multifunctional DNA hybrid nanospheres through coordination-driven self-assembly. Angew Chem Int Ed. 2019;58(5):1350-4.

162. Wang R. Gasotransmitters: growing pains and joys. Trends Biochem Sci. 2014;39(5):227-32.

163. Paul BD, Snyder $\mathrm{SH}$. $\mathrm{H}_{2} \mathrm{~S}$ : a novel gasotransmitter that signals by sulfhydration. Trends Biochem Sci. 2015;40(11):687-700.

164. Hu L-F, Lu M, Tiong CX, Dawe GS, Hu G, Bian J-S. Neuroprotective effects of hydrogen sulfide on Parkinson's disease rat models. Aging Cell. 2010;9(2):135-46.

165. Wallace JL, Wang R. Hydrogen sulfide-based therapeutics: exploiting a unique but ubiquitous gasotransmitter. Nat Rev Drug Discov. 2015;14(5):329-45.

166. Wang R. Physiological implications of hydrogen sulfide: a whiff exploration that blossomed. Physiol Rev. 2012;92(2):791-896.

167. Liu J, Liu Y, Bu W, Bu J, Sun Y, Du J, Shi J. Ultrasensitive nanosensors based on upconversion nanoparticles for selective hypoxia imaging in vivo upon near-infrared excitation. J Am Chem Soc. 2014;136(27):9701-9.

168. Wang M, Chen Z, Zheng W, Zhu H, Lu S, Ma E, Tu D, Zhou S, Huang M, Chen X. Lanthanide-doped upconversion nanoparticles electrostatically coupled with photosensitizers for near-infrared-triggered photodynamic therapy. Nanoscale. 2014;6(14):8274-82.

169. Zhang J, Yuan Y, Yu Z-L, Yu A, Yu S-H. Selective detection of ferric ions by blue-green photoluminescent nitrogen-doped phenol formaldehyde resin polymer. Small. 2014;10(18):3662-6.

170. Dolmans D, Fukumura D, Jain RK. Photodynamic therapy for cancer. Nat Rev Cancer. 2003;3(5):380-7.

171. Lal S, Clare SE, Halas NJ. Nanoshell-enabled photothermal cancer therapy: impending clinical impact. Acc Chem Res. 2008;41(12):1842-51.

172. Cheng L, Wang C, Feng L, Yang K, Liu Z. Functional nanomaterials for phototherapies of cancer. Chem Rev. 2014;114(21):10869-939. 
173. Liang C, Xu L, Song G, Liu Z. Emerging nanomedicine approaches fighting tumor metastasis: animal models, metastasis-targeted drug delivery, phototherapy, and immunotherapy. Chem Soc Rev. 2016;45(22):6250-69.

174. Huang X, Zhang W, Guan G, Song G, Zou R, Hu J. Design and functionalization of the NIR-responsive photothermal semiconductor nanomaterials for cancer theranostics. Acc Chem Res. 2017;50(10):2529-38.

175. Zhang Z, Wang J, Nie X, Wen T, Ji Y, Wu X, Zhao Y, Chen C. Near infrared laser-induced targeted cancer therapy using thermoresponsive polymer encapsulated gold nanorods. J Am Chem Soc. 2014;136(20):7317-26.

176. Huang X, El-Sayed IH, Qian W, El-Sayed MA. Cancer cell imaging and photothermal therapy in the near-infrared region by using gold nanorods. J Am Chem Soc. 2006;128(6):2115-20.

177. SuY, Wei X, Peng F, Zhong Y, LuY, Su S, XU T, Lee ST, He Y. Gold nanoparticles-decorated silicon nanowires as highly efficient nearinfrared hyperthermia agents for cancer cells destruction. Nano Lett. 2012;12(4):1845-50

178. Liu H, Chen D, Li L, Liu T, Tan L, Wu X, Tang F. Multifunctional gold nanoshells on silica nanorattles: a platform for the combination of photothermal therapy and chemotherapy with low systemic toxicity. Angew Chem Int Ed. 2011;50(4):891-5.

179. Dong Q, Wang X, Hu X, Xiao L, Zhang L, Song L, Xu M, Zou Y, Chen $L$, Chen Z, Tan W. Simultaneous application of photothermal therapy and an anti-inflammatory prodrug using pyrene-aspirinloaded gold nanorod graphitic nanocapsules. Angew Chem Int Ed. 2018:57(1):177-81.

180. Huang P, Lin J, Li W, Rong P, Wang Z, Wang S, Wang X, Sun X, Aronova M, Niu G, Leapman RD, Nie Z, Chen X. Biodegradable gold nanovesicles with an ultrastrong plasmonic coupling effect for photoacoustic imaging and photothermal therapy. Angew Chem Int Ed. 2013;52(52):13958-64

181. Liang C, Diao S, Wang C, Gong H, Liu T, Hong G, Shi X, Dai H, Liu Z Tumor metastasis inhibition by imaging-guided photothermal therapy with single-walled carbon nanotubes. Adv Mater. 2014;26(32):5646-52.

182. Robinson JT, Tabakman SM, Liang Y, Wang H, Casalongue HS, Vinh D, Dai $\mathrm{H}$. Ultrasmall reduced graphene oxide with high near-infrared absorbance for photothermal therapy. J Am Chem Soc. 2011;133(17):6825-31.

183. Lin H, Gao S, Dai C, Chen Y, Shi J. A two-dimensional biodegradable niobium carbide (MXene) for photothermal tumor eradication in NIRand NIR-II biowindows. J Am Chem Soc. 2017;139(45):16235-47.

184. Zhou Z, Wang Y, Yan Y, Zhang Q, Cheng Y. Dendrimer-templated ultrasmall and multifunctional photothermal agents for efficient tumor ablation. ACS Nano. 2016;10(4):4863-72.

185. Zhang L, Gao S, Zhang F, Yang K, Ma Q, Zhu L. Activatable hyaluronic acid nanoparticle as a theranostic agent for optical/photoacoustic image-guided photothermal therapy. ACS Nano. 2014;8(12):12250-8.

186. Zhou M, Zhang R, Huang M, Lu W, Song S, Melancon MP, Tian M, Liang D, Li C. A chelator-free multifunctional [64Cu]CuS nanoparticle platform for simultaneous micro-PET/CT imaging and photothermal ablation therapy. J Am Chem Soc. 2010;132(43):15351-8.

187. Tian Q, Hu J, Zhu Y, Zou R, Chen Z, Yang S, Li R, Su Q, Han Y, Liu X. Sub-10 nm Fe304@Cu(2-x)S core-shell nanoparticles for dual-modal imaging and photothermal therapy. J Am Chem Soc. 2013;135(23):8571-7.

188. Ni D, Jiang D, Valdovinos HF, Ehlerding EB, Yu B, Barnhart TE, Huang P, Cai W. Bioresponsive polyoxometalate cluster for redox-activated photoacoustic imaging-guided photothermal cancer therapy. Nano Lett. 2017;17(5):3282-9.

189. Cheng Y, Chang Y, Feng Y, Jian H, Tang Z, Zhang H. Deep-level defect enhanced photothermal performance of bismuth sulfide-gold heterojunction nanorods for photothermal therapy of cancer guided by computed tomography imaging. Angew Chem Int Ed. 2018;57(1):246-51.

190. He H, Ji S, He Y, Zhu A, Zou Y, Deng Y, Ke H, Yang H, Zhao Y, Guo Z, Chen H. Photoconversion-tunable fluorophore vesicles for wavelengthdependent photoinduced cancer therapy. Adv Mater. 2017. https://doi. org/10.1002/adma.201606690

191. Zou Q, Abbas M, Zhao L, Li S, Shen G, Yan X. Biological photothermal nanodots based on self-assembly of peptide-porphyrin conjugates for antitumor therapy. J Am Chem Soc. 2017;139(5):1921-7.
192. Zhen X, Xie C, Jiang Y, Ai X, Xing B, Pu K. Semiconducting photothermal nanoagonist for remote-controlled specific cancer therapy. Nano Lett. 2018;18(2):1498-505.

193. Guo B, Sheng Z, Hu D, Li A, Xu S, Manghnani PN, Liu C, Guo L, Zheng $\mathrm{H}$, Liu B. Molecular engineering of conjugated polymers for biocompatible organic nanoparticles with highly efficient photoacoustic and photothermal performance in cancer theranostics. ACS Nano. 2017;11(10):10124-34.

194. Jung HS, Lee JH, Kim K, Koo S, Verwilst P, Sessler JL, Kang C, Kim JS. A mitochondria-targeted cryptocyanine-based photothermogenic photosensitizer. J Am Chem Soc. 2017;139(29):9972-8.

195. Qi J, Fang Y, Kwok RTK, Zhang X, Hu X, Lam JWY, Ding D, Tang BZ. Highly stable organic small molecular nanoparticles as an advanced and biocompatible phototheranostic agent of tumor in living mice. ACS Nano. 2017;11(7):7177-88.

196. Shanmugam V, Selvakumar S, Yeh C-S. Near-infrared lightresponsive nanomaterials in cancer therapeutics. Chem Soc Rev. 2014;43(17):6254-87.

197. Robinson JT, Tabakman SM, Liang Y, Wang H, Casalongue HS, Daniel V, Dai H. Ultrasmall reduced graphene oxide with high nearinfrared absorbance for photothermal therapy. J Am Chem Soc. 2011;133(17):6825-31.

198. Kanchi S, Singh P, Bisetty K. Dithiocarbamates as hazardous remediation agent: a critical review on progress in environmental chemistry for inorganic species studies of 20th century. Arab J Chem. 2014;7(1):11-25.

199. Wang Y, Xie Y, Li J, Peng Z-H, Sheinin Y, Zhou J, Oupicky D. Tumor-penetrating nanoparticles for enhanced anticancer activity of combined photodynamic and hypoxia-activated therapy (vol 11, pg 2227, 2017) ACS Nano. 2019;13(4):4855-4855.

200. Jin Q, Deng Y, Jia F, Tang Z, Ji J. Gas therapy: an emerging "green" strategy for anticancer therapeutics. Adv Ther. 2018;1 (6):1800084.

201. Wang Y, Xie Y, Li J, Peng ZH, Sheinin Y, Zhou J, Oupický D. Tumorpenetrating nanoparticles for enhanced anticancer activity of combined photodynamic and hypoxia-activated therapy. ACS Nano. 2017:11(2):2227-38.

202. Bai JX, Cederbaum Al. Catalase protects HepG2 cells from apoptosis induced by DNA-damaging agents by accelerating the degradation of p53. J Biol Chem. 2003;278(7):4660-7.

203. Sharma J, Goyal PK. Chemoprevention of chemical-induced skin cance by Panax ginseng root extract. J Ginseng Res. 2015;39(3):265-73.

204. He Q. Precision gas therapy using intelligent nanomedicine. Biomater Sci. 2017;5(11):2226-30

205. Fan W, Yung BC, Chen X. Stimuli-responsive NO release for On-Demand gas-sensitized synergistic cancer therapy. Angew Chem Int Ed. 2018;57(28):8383-94.

206. Dole M, Wilson FR, Fife WP. Hyperbaric hydrogen therapy: a possible treatment for cancer. Science. 1975;190(4210):152-4

207. Fukuda K-I, Asoh S, Ishikawa M, Yamamoto Y, Ohsawa I, Ohta S. Inhalation of hydrogen gas suppresses hepatic injury caused by ischemia/ reperfusion through reducing oxidative stress. Biochem Biophys Res Commun. 2007;361(3):670-4.

208. Ohno K, Ito M, Ichihara M, Ito M. Molecular hydrogen as an emerging therapeutic medical gas for neurodegenerative and other diseases. Oxid Med Cell Longev. 2012. https://doi.org/10.1155/2012/353152.

209. Yang T, Jin Z, Wang Z, Zhao P, Zhao B, Fan M, Chen L, Wang T, Su B-L, He Q. Intratumoral high-payload delivery and acid-responsive release of $\mathrm{H}_{2}$ for efficient cancer therapy using the ammonia borane-loaded mesoporous silica nanomedicine. Appl Mater Today. 2018;11:136-43.

210. Rocha JS, Barbosa MJ, Wijffels RH. Hydrogen production by photosynthetic bacteria : culture media, yields and efficiencies. Biohydrogen. 2001;II(23):3-32.

211. He Y, Zhang B, Chen Y, Jin Q, Wu J, Yan F, Zheng H. Image-guided hydrogen gas delivery for protection from myocardial ischemia-reperfusion injury via microbubbles. ACS Appl Mater Interfaces. 2017;9(25):21190-9.

212. Zhang B, Wang F, Zhou H, Gao D, Yuan Z, Wu C, Zhang X. Polymer dots compartmentalized in liposomes as a photocatalyst for in situ hydrogen therapy. Angew Chem Int Ed. 2019;58(9):2744-8.

213. Zhao P, Jin Z, Chen Q, Yang T, Chen D, Meng J, Lu X, Gu Z, He Q. Local generation of hydrogen for enhanced photothermal therapy. Nat Commun. 2018. https://doi.org/10.1038/s41467-018-06630-2. 
214. Melamed JR, Edelstein RS, Day ES. Elucidating the fundamental mechanisms of cell death triggered by photothermal therapy. ACS Nano. 2015;9(1):6-11.

215. Trachootham D, Alexandre J, Huang P. Targeting cancer cells by ROSmediated mechanisms: a radical therapeutic approach? Nat Rev Drug Discov. 2009;8(7):579-91.

216. Nekouei F, Nekouei S, Pouzesh M, Liu Y. Porous-CdS/ $\mathrm{Cu}_{2} \mathrm{O} / \mathrm{graphitic}$ $\mathrm{C}_{3} \mathrm{~N}_{4}$ dual p-n junctions as highly efficient photo/catalysts for degrading ciprofloxacin and generating hydrogen using solar energy. Chem Eng J. 2020. https://doi.org/10.1016/j.cej.2019.123710.

217. Liu D, Zhang S, Wang J, Peng T, Li R. Direct Z-scheme 2D/2D photocatalyst based on ultrathin $\mathrm{g}-\mathrm{C}_{3} \mathrm{~N}_{4}$ and $\mathrm{WO}_{3}$ nanosheets for efficient visible-light-driven $\mathrm{H}_{2}$ generation. ACS Appl Mater Interfaces. 2019;11(31):27913-23.

218. Holohan C, Van Schaeybroeck S, Longley DB, Johnston PG. Cancer drug resistance: an evolving paradigm. Nat Rev Cancer. 2013;13(10):714-26.

219. Wang J, Seebacher N, Shi H, Kan Q, Duan Z. Novel strategies to prevent the development of multidrug resistance (MDR) in cancer. Oncotarget. 2017;8(48):84559-71.

220. Bai JL, Meng ZQ. Expression of apoptosis-related genes in livers from rats exposed to sulfur dioxide. Toxicology. 2005;216(2-3):253-60.

221. Meng ZQ, Liu YX, Wu DM. Effect of sulfur dioxide inhalation on cytokine levels in lungs and serum of mice. Inhal Toxicol. 2005;17(6):303-7.

222. Wang X-B, Huang X-M, Ochs T, Li X-Y, Jin H-F, Tang C-S, Du J-B. Effect of sulfur dioxide preconditioning on rat myocardial ischemia/reperfusion injury by inducing endoplasmic reticulum stress. Basic Res Cardiol. 2011;106(5):865-78.

223. Zhao M-m, Yang J-y, Wang X-b, Tang C-s, Du J-b, Jin H-f. The PI3K Akt pathway mediates the protection of $\mathrm{SO}_{2}$ preconditioning against myocardial ischemia/reperfusion injury in rats. Acta Pharmacol Sin. 2013;34(4):501-6.

224. Shen W, Liu W, Yang H, Zhang P, Xiao C, Chen X. A glutathioneresponsive sulfur dioxide polymer prodrug as a nanocarrier for combating drug-resistance in cancer chemotherapy. Biomaterials. 2018;178:706-19.

225. Day JJ, Neill DL, Xu S, Xian M. Benzothiazole sulfinate: a sulfinic acid transfer reagent under oxidation-free conditions. Org Lett. 2017;19(14):3819-22.

226. Jeong YC, Park DG, Kim E, Ahn KH, Yang SI. Fatigue-resistant photochromic dithienylethenes by controlling the oxidation state. Chem Commun. 2006;17:1881-3.

227. Szakacs G, Paterson JK, Ludwig JA, Booth-Genthe C, Gottesman MM. Targeting multidrug resistance in cancer. Nat Rev Drug Discov. 2006;5(3):219-34

228. Karwicka E. Role of glutathione in the multidrug resistance in cancer. Postepy Biol Komorki. 2010;37(2):323-41

229. Green JA, Vistica DT, Young RC, Hamilton TC, Rogan AM, Ozols RF. Potentiation of melphalan cytotoxicity in human ovarian cancer cell lines by glutathione depletion. Cancer Res. 1984;44(11):5427-31.

230. Meng ZQ, Qin GH, Zhang B. DNA damage in mice treated with sulfur dioxide by inhalation. Environ Mol Mutagen. 2005;46(3):150-5.

231. Paciotti GF, Myer LD, Kim TH, Wang S, Alexander HR, Weinreich D, Tamarkin L. Colloidal gold: a novel colloidal nanoparticle vector for tumor-directed drug delivery. Clin Cancer Res. 2001;7(11):3673S-3674S.

\section{Publisher's Note}

Springer Nature remains neutral with regard to jurisdictional claims in published maps and institutional affiliations.

Ready to submit your research? Choose BMC and benefit from:

- fast, convenient online submission

- thorough peer review by experienced researchers in your field

- rapid publication on acceptance

- support for research data, including large and complex data types

- gold Open Access which fosters wider collaboration and increased citations

- maximum visibility for your research: over $100 \mathrm{M}$ website views per year

At BMC, research is always in progress.

Learn more biomedcentral.com/submissions 